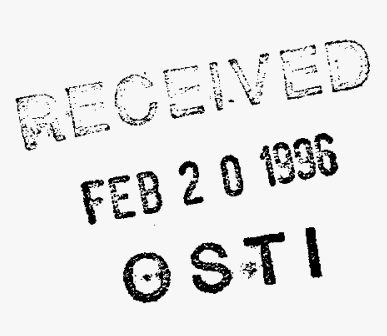

UCRL-ID-123017

\title{
Implications of Mining Practices in an Open-Pit Gold Mine for Monitoring of a Comprehensive Test-Ban Treaty
}

\author{
S. P. Jarpe \\ B. Moran \\ P. Goldstein \\ L.A. Glenn \\ This paper is submitted as \\ CTBT Seismic Monitoring Project Task S7.2, Deliverable \#3
}

January 1996

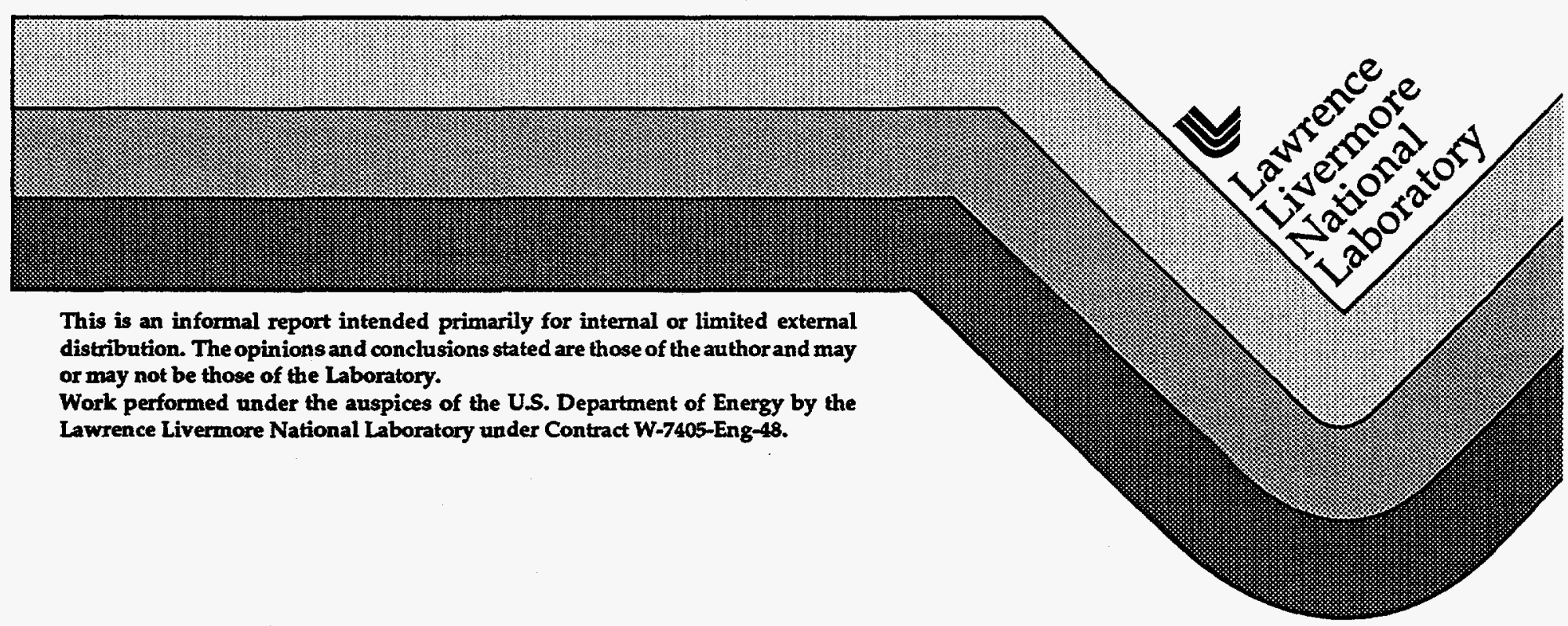




\section{DISCLAIMER}

This document was prepared as an account of work sponsored by an agency of the United States Government. Neither the United States Government nor the University of California nor any of their employees, makes any warranty, express or implied, or assumes any legal liability or responsibility for the accuracy, completeness, or usefulness of any information, apparatus, product, or process disclosed, or represents that its use would not infringe privately owned rights. Reference herein to any specific commercial product, process, or service by trade name, trademark, manufacturer, or otherwise, does not necessarily constitute or imply its endorsement, recommendation, or favoring by the United States Government or the University of California. The views and opinions of authors expressed herein do not necessarily state or reflect those of the United States Government or the University of California, and shall not be used for advertising or product endorsement purposes.

This report has been reproduced directly from the best available copy.

Available to DOE and DOE contractors from the

Office of Scientific and Technical Information

P.O. Box 62, Oak Ridge, TN 37831

Prices available from (615) 576-8401, FTS 626-8401

Available to the public from the

National Technical Information Service

U.S. Department of Commerce

5285 Port Royal Rd.

Springfield, VA 22161 


\section{DISCLAMMER}

Portions of this document may be illegible in electronic image products. Images are produced from the best available original document. 


\title{
FINAL REPORT
}

\section{Implications of Mining Practices in an Open-Pit Gold Mine for Monitoring of a Comprehensive Test-Ban Treaty}

\author{
S. P. Jarpe, B. Moran, P. Goldstein, and L. A. Glenn
}

\begin{abstract}
This report summarizes the results of an experiment at the Gold Quarry pit, operated by the Newmont Gold Company at Carlin, NV. The purpose of the experiment was to obtain local and regional seismic data, together with "ground truth", from conventional surface blasting activity and to use these data to help determine the effectiveness with which conventional mining blasts can be discriminated from underground nuclear explosions.
\end{abstract}

\subsection{Introduction}

It is well known that chemical explosions can appear on seismic records as nuclear explosions under the right conditions. It is obviously important, in monitoring a comprehensive test ban treaty (CTBT), to be able to distinguish one from the other since mines throughout the world routinely employ chemical explosives in large quantities. In conventional mining practice, large-scale explosions are normally conducted in what is known as ripple-fired mode. With this technique, an array of holes is drilled, filled with explosive, tamped, and then fired in a spatial and temporal sequence designed to obtain maximum efficiency in rock comminution while, at the same time, reducing to a minimum material thrown into the air and ground motions in areas proximal to the mine. It is easy to show that the seismic signature from this kind of explosion can, in principle at least, be distinguished from that produced by a concentrated charge. In the former case, and for simple shot patterns and delays, a regular, time-independent spectral modulation is predicted in the coda, where the characteristic frequency is inversely proportional to the programmed delay. Spectral modulation has been observed by several investigators [Stump and Reamer (1988), Smith (1989), Hedlin et al. $(1989,1990)$, Chapman et al. (1992), Kim et al. (1994)]. When the shot patterns are not simple and the delays sufficiently irregular, however, the spectral modulation may diminish or disappear altogether.

As suggested by the conventional practice, ripple firing also is predicted to reduce the amplitude of the seismic signal by up to several orders of magnitude. It has been argued [Richards (1994)] that the great majority of mining blasts are unlikely to be confused for underground nuclear explosions because only about 10 to 30 chemical explosions per year with magnitudes greater than 3.0 are detected teleseismically in the U.S 
(and, by extension, the number worldwide would presumably not be significantly greater). However, clandestine nuclear explosions would likely be carried out in large cavities; assuming, conservatively, that an amplitude decoupling factor of 50 is achieved in such a cavity, a kiloton nuclear explosion would produce an $m_{b}$ of 2.1 (based on the scale developed by Vergino and Mensing [1990] for the Nevada Test Site). Clearly, a much larger number of mines worldwide perform explosions at this level. Hence, even the verification of a kiloton threshold would require discriminating between many mine explosions each day and the (hopefully) occasional attempt at evasion. Moreover, a determined evader might specifically choose to eschew ripple-fired practice in order to invite an on-site inspection -- which would reveal no evidence of nuclear testing and thus establish credibility that bona fide mining was indeed taking place. After having established this credibility, cavity decoupled nuclear explosions might then be periodically substituted for the routine blasting.

To shed more light on the effects of mining practices on the monitoring of a CTBT, the LLNL Treaty Verification Program has conducted an investigation of surface mining blasts in metamorphic rock in the Carlin, NV area. The main objectives of the Carlin investigation were:

- Assess the effectiveness of methods to identify ripple-fired explosions based on timeindependent spectral modulation and determine under what explosive firing conditions these methods are not effective.

- Identify explosion firing conditions that produce seismic signals that appear to be concentrated explosions and determine the relative frequency of these events.

- Determine the relationship between the seismic magnitudes of mining explosions and explosion parameters such as total yield and firing parameters.

\subsection{Data Collection}

\subsection{Newmont Gold Company Ground Truth Data}

We obtained the cooperation of the Newmont Gold Company (NGC), which operates an extensive open-pit gold mining operation in the Carlin, NV area. Their largest pit is the Gold Quarry, in which they conduct 2-3 25- to 150-ton explosions each week. Our temporary deployment, which began April 11,1995 and continued until Sept 20, 1995, employed between 1 and 7 portable seismic recorders. The locations of these portable stations are shown in Figure 1. Figure 2 shows a photograph of the NGC operations in the Gold Quarry.

We obtained detailed information about the mining blasts from the NGC. This information includes shot geometry, amount of explosive in each hole, and delay times 


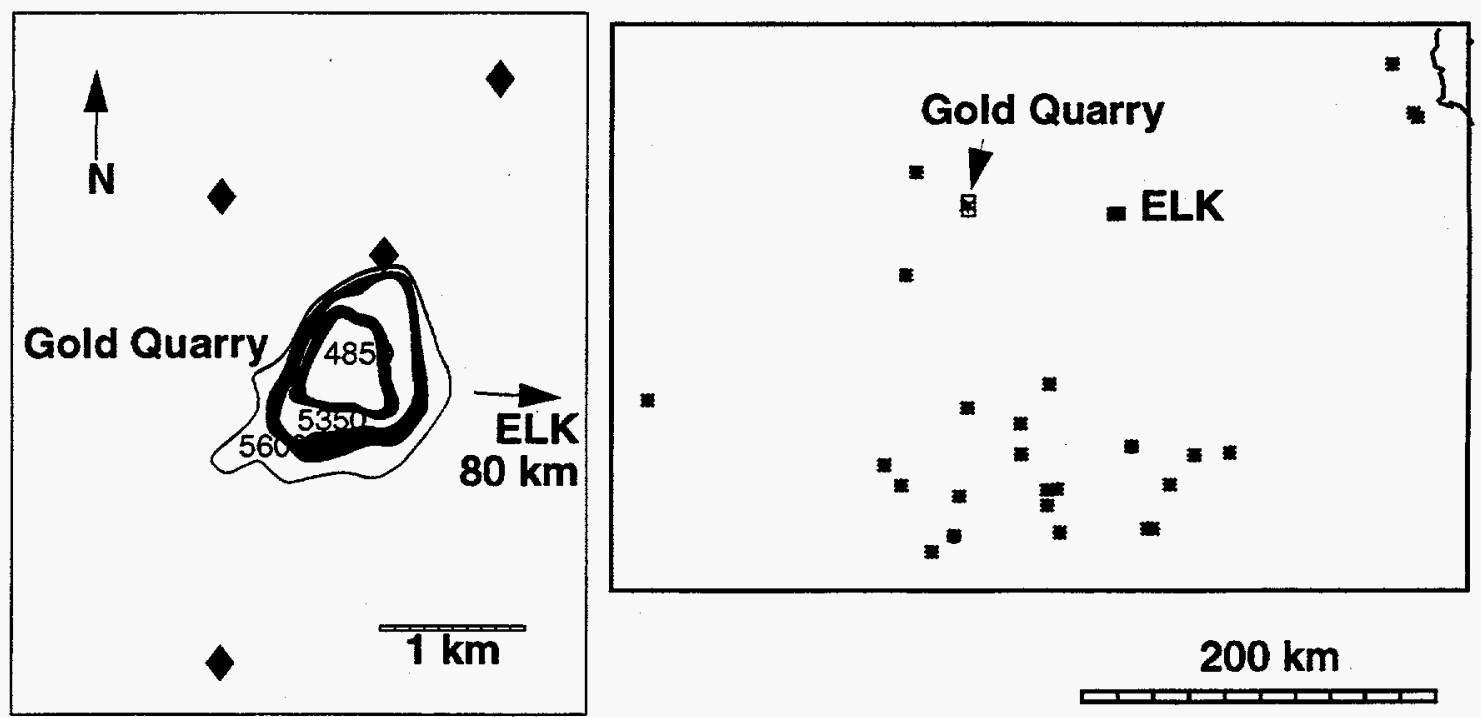

Figure 1. Location map. The diamond symbols are the locations of the temporary seismic recording sites, and the square shows the location of the LLNL permanent station, ELK. The inset (location shown by box on base map) shows the Gold Quarry area in detail. The unshaded regions are the main working levels in the Gold Quarry pit, which are at the 4850, 5350, and 5600 foot elevations (above sea level). The *symbols on the right-hand map are the locations of the earthquakes used in the study.

between shot holes. The close-in seismic stations allowed us to positively identify the times and locations of the mining blasts.

The NGC provided blasting logs for most of the shots that they conducted at Gold Quarry during our deployment period. These logs consisted of diagrams of the shot hole positions and the order in which the holes were fired, the average amount of explosive in each hole, and the delays between each group of shots. Figure 3 is a sample of the information provided for one shot. In Appendix A we summarize the shot information for all the shots that we were able to unambiguously correlate with the seismic signals. Table A1 summarizes the relevant explosion parameters for these shots and Figure A1 shows the locations of the shots in the pit.

The blasting logs did not provide the exact time of each shot, so we used our close-in seismic stations to determine the times. The Newmont blasters frequently fire more than one shot at a time. The individual shots are from 5 seconds to several minutes apart. Shots fired less than 2 seconds apart do not appear as separate signals at distances greater than about $50 \mathrm{~km}$, so we combined the information for shots fired in close succession to form an aggregate or total shot pattern.

The primary data used in the analysis of the Carlin explosions derive from a regional seismic station, ELK, which is located $80 \mathrm{~km}$ to the east of NGC's Gold Quarry. This sta- 


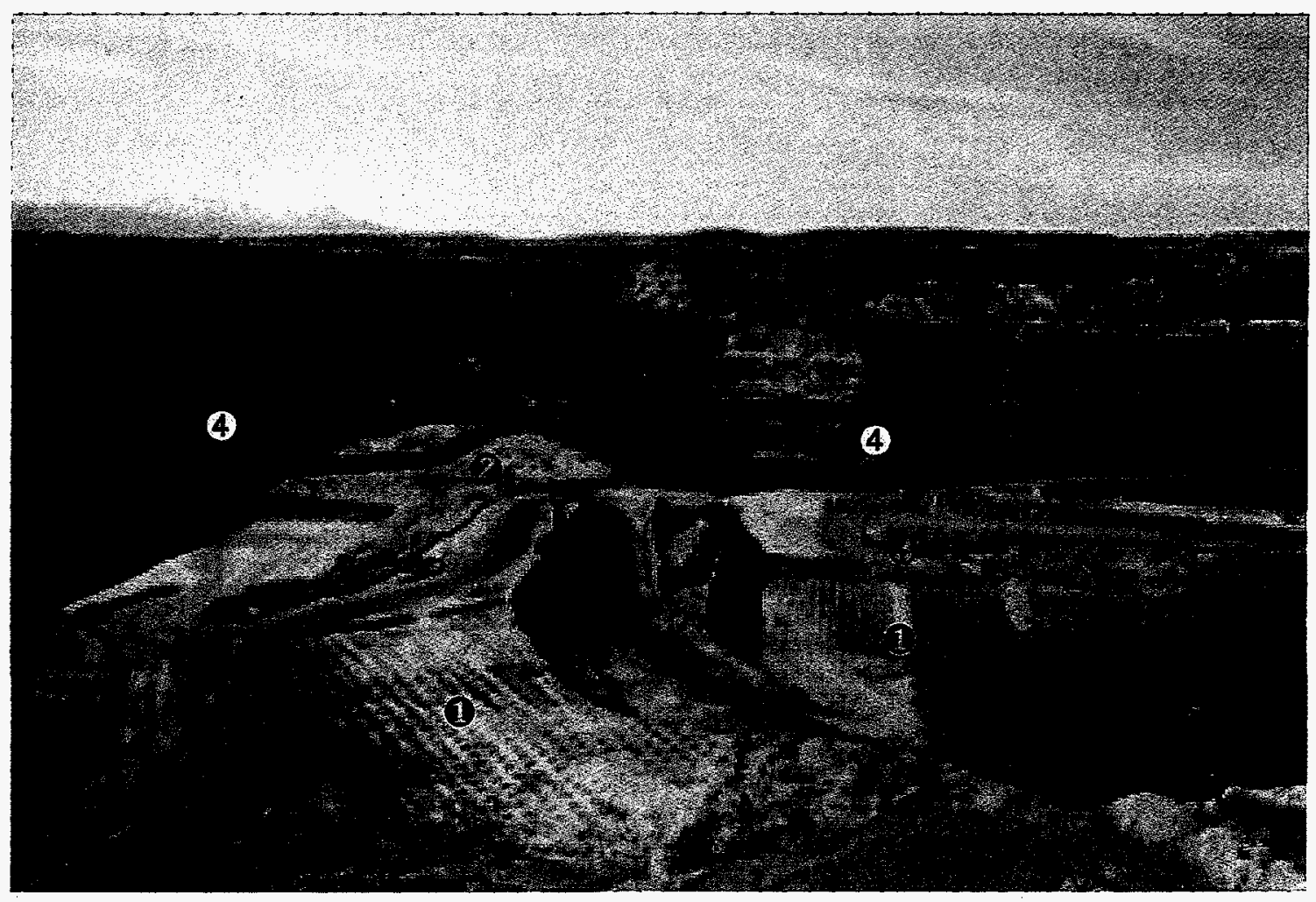

Figure 2. View of activities in the Gold Quarry pit. 1 are shot patterns that have been drilled and are ready for the explosive to be loaded. 2 are areas where shots have been conducted. 3 are areas where ore is being removed by a loader. are vertical rock faces that are called "highwalls".

tion is operated by LLNL, and is part of the 4-station Livermore Nevada Network (LNN) originally established to measure the yields of underground nuclear explosions at the Nevada Test Site (NTS). The ELK station consists of a broadband Guralp sensor and a 24-bit Reftek recorder. The 3-component seismic data are recorded continuously and have an effective bandwidth of 0.01 to $35 \mathrm{~Hz}$.

\subsection{Newmont Gold Company Explosion Database}

The origin times of the explosions listed in Table A1 were obtained from the LLNL seismic stations near the Gold Quarry and were used to extract the corresponding time segments from the ELK station. In some cases, signals from mining blasts other than the one for which we had established ground truth arrived at ELK during the coda of the explosion of interest, which precluded the accurate estimation of coda magnitude for that explosion.

\subsection{Earthquake Database}

To evaluate the performance of methods to discriminate between ripple-fired explosions and earthquakes, we assembled a dataset of ELK waveforms for 49 earthquakes 


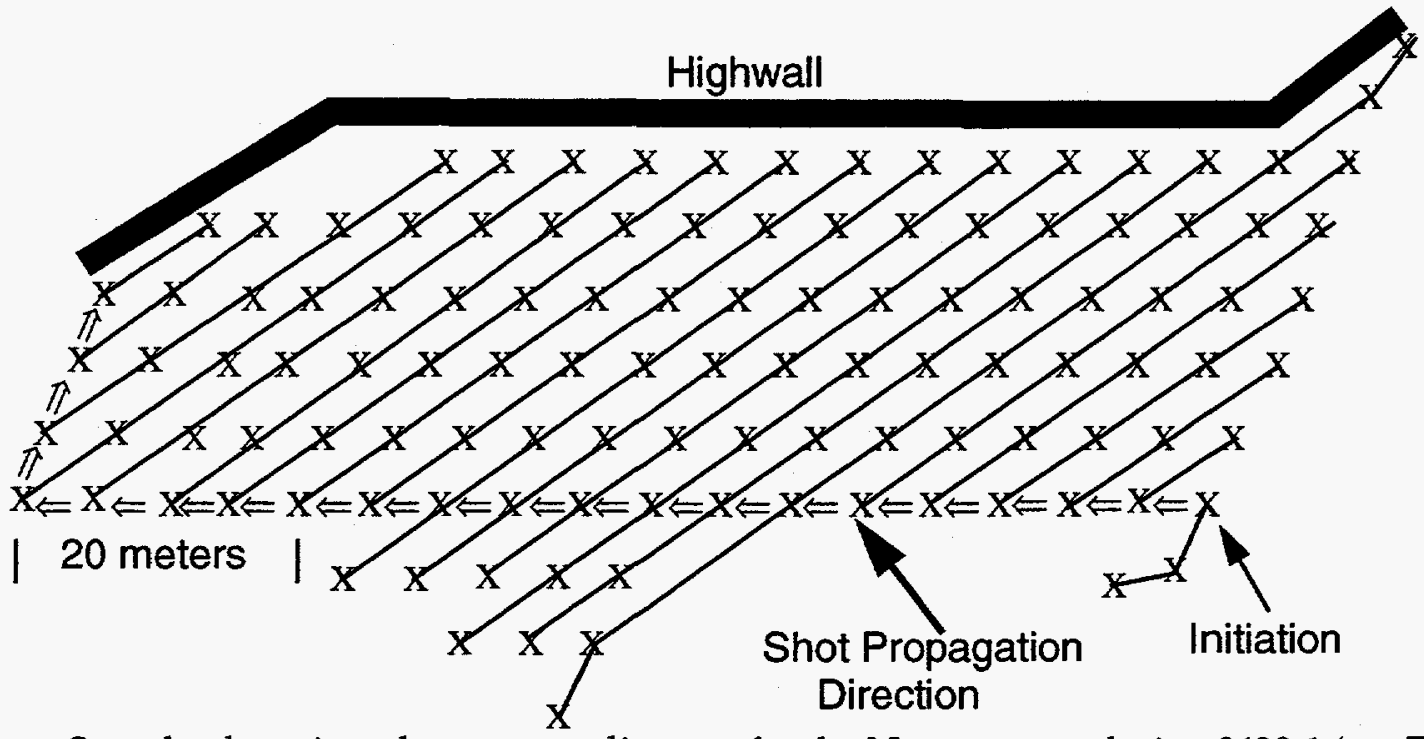

Figure 3. Sample plan-view shot pattern diagram for the Newmont explosion 0420-1 (see Table 1). The $X$-symbols are the locations of the individual shot holes, and the solid lines show how the holes in an individual shot delay (group of shots fired simultaneously) are tied together by detonating cord. The small double-arrows represent the delays (65 milliseconds for this shot) between groups of shots. The highwall is the vertical face rising upward from the horizontal bench in which the shot is fired, and the remaining perimeter is a vertical surface 7.5 meters high extending downward from the bench surface.

from the northern Nevada region. Figure 1 includes a map showing the locations of these earthquakes, which ranged in magnitude from 0.7 to 3.7 .

\subsection{Data Analysis}

In this section we first describe how we obtained magnitudes from the seismic data. Next, we describe how the time-frequency distributions of the seismic waveforms were obtained for discriminant analysis. Last, we provide useful statistics about the relative frequency of the different types of blasting activity and discuss the effect of shot parameters on the seismic magnitude.

\subsection{Measurement of Seismic Magnitudes}

Magnitudes for the Carlin explosions were calculated from data recorded at ELK using the coda method of Mayeda (1993) because it was found that, for NTS explosions, the random errors (standard deviation) in the single-station coda magnitudes were a factor of 6 smaller than for other single-station magnitude measurements. Also, because of the relatively short distance from the mine to our furthest recording station, $P_{n}$-phase amplitudes would not be readily available.

We used ELK station recordings to calibrate the coda magnitude scale. For each NTS explosion, we determined the network averaged $P_{n}$-phase amplitude, $A_{P n}$, as well as 


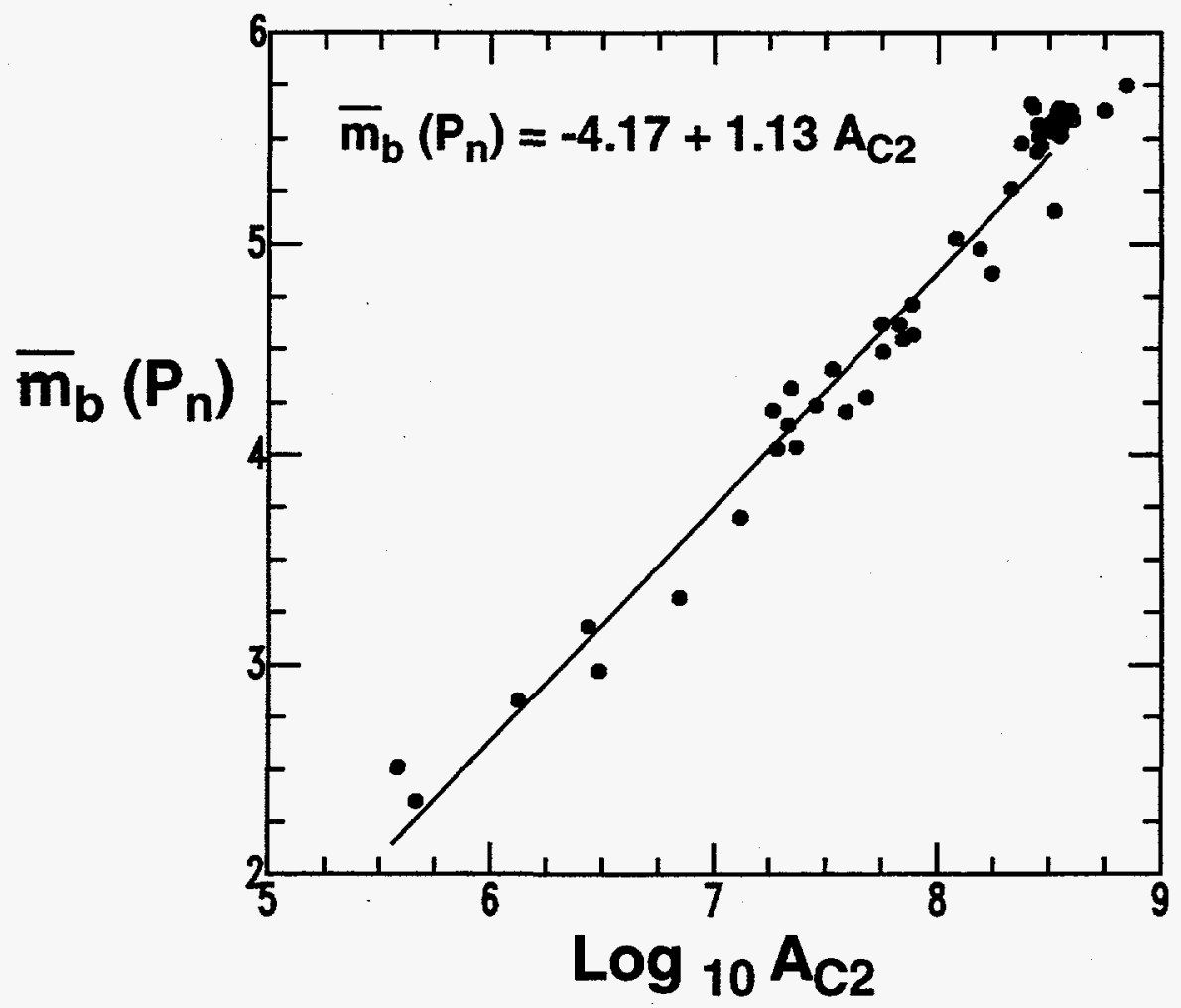

Figure 4. $\bar{m}_{b}\left(P_{n}\right)$ as a function of coda amplitude for 48 NTS explosions recorded at ELK. The data points were used to calculate the linear fit shown. Distance corrections were made by assuming that the coda amplitude is proportional $1 / \mathrm{r}^{\gamma}$, where $\gamma$ is 0.3 and $\mathrm{r}$ is the distance in $\mathrm{km}$.

$\mathrm{A}_{\mathrm{C} 2}$, the average (of the two horizontal recordings at ELK) of the distance corrected "coda amplitude" measurements (see Mayeda and Walter, 1995) from the 1-2 Hz band. The distance corrections were made assuming that coda amplitude is proportional to $r^{-\gamma}$, where $\gamma$ is 0.3 (appropriate for northern Nevada; Mayeda, personal communication) and $r$ is the epicentral distance in $\mathrm{km}$. From the measured values of $A_{P n}$ we determined $\overline{\mathrm{m}}_{\mathrm{b}}$, the (four-station) network averaged $\mathrm{m}_{\mathrm{b}}\left(\mathrm{P}_{\mathrm{n}}\right)$, using the correlation obtained by Denny et al. (1987). We then calculated the best-fitting linear relationship between the logarithm of $A_{C 2}$ and $\bar{m}_{b}$. The resulting line is shown in Figure 4.

We used this relationship to calculate $\bar{m}_{b}$ from the measured values of $A_{C 2}$ for the mining explosions in this study. Note that the lowest magnitude used in determining the fit to the explosions was $\bar{m}_{b}=2.3$ and all of the mining explosions examined in the present study had magnitudes less than this value, so that the regression line had to be extrapolated to calculate equivalent magnitudes.

In a preliminary report on this study (Jarpe et al, 1995), we used a different method 
of estimating magnitude. Instead of employing the NTS-explosion data base, we used local magnitudes, $\mathrm{m}_{\mathrm{L}}$, derived from small, shallow earthquakes in the Carlin region, recorded at ELK, and whose $\mathrm{m}_{\mathrm{L}}$ values were listed in the University of Nevada-Reno event catalog. Just as with the $\mathrm{P}_{\mathrm{n}}$-phase amplitude data, a regression line was fitted to the $m_{L}-A_{C 2}$ data. It was found that, when the measured value of $A_{C 2}$ for the kilotonlevel-chemical explosion called the Non-Proliferation Experiment (Denny, 1994) was substituted in the derived regression formula, the value of $\mathrm{m}_{\mathrm{L}}$ predicted was exactly the same as the measured value of $\overline{\mathrm{m}}_{\mathrm{b}}$, namely 4.16 (Walter et al, 1994). However, the slope of the regression line was significantly less, so that the extrapolated magnitudes derived from the coda-amplitude measurements on the Carlin explosions were substantially higher. The present method, which uses NTS explosion data to calibrate the magnitude scale, provides a more consistent basis for magnitude evaluation, especially when the principal goal is to compare magnitudes from commercial blasting with those from underground nuclear explosions.

\subsection{Calculation of Spectrograms and Binary Sonograms}

As noted above, the observation of time independent spectral modulations is a very good indication that an event involved ripple firing. Time independent spectral modulation is usually identified by continuous peaks in plots of spectral amplitude, or some closely related measurement, as a function of time (e.g., Hedlin et al. [1989]; Wüster [1990]). We use high-resolution spectrograms and binary sonograms (e.g., Figure 5) to identify events with time-independent spectral modulation. Our spectrograms consist of a time-sequence of high-resolution spectral amplitude estimates. Each estimate is obtained by windowing a two-second segment of data, then employing a 5\% Hamming taper, computing the data autocorrelation function, and finally computing a maximum entropy or maximum likelihood power spectral estimate. There is one second of overlap between successive windows. The 2-second windowing and 1-second overlap periods result in energy appearing to arrive 1-2 seconds early in a spectogram/sonogram with respect to the seismogram. Color spectrograms are obtained by converting the spectral amplitudes to integers between zero and 255 and assigning a color to all 256 integers. We compute binary sonograms by taking the difference between a spectrogram that has been smoothed over a $10 \mathrm{~Hz}$ bandwidth and the unsmoothed spectrogram, and setting all the resulting negative values to zero and all positive values to one. Black and white sonograms are obtained by assigning all points with the value of one to black and all points with the value of zero to white. Time-independent spectral modulation is represented by continuous horizontal bands in the color spectrograms and black and white sonograms, that are not present in the pre-event noise. 

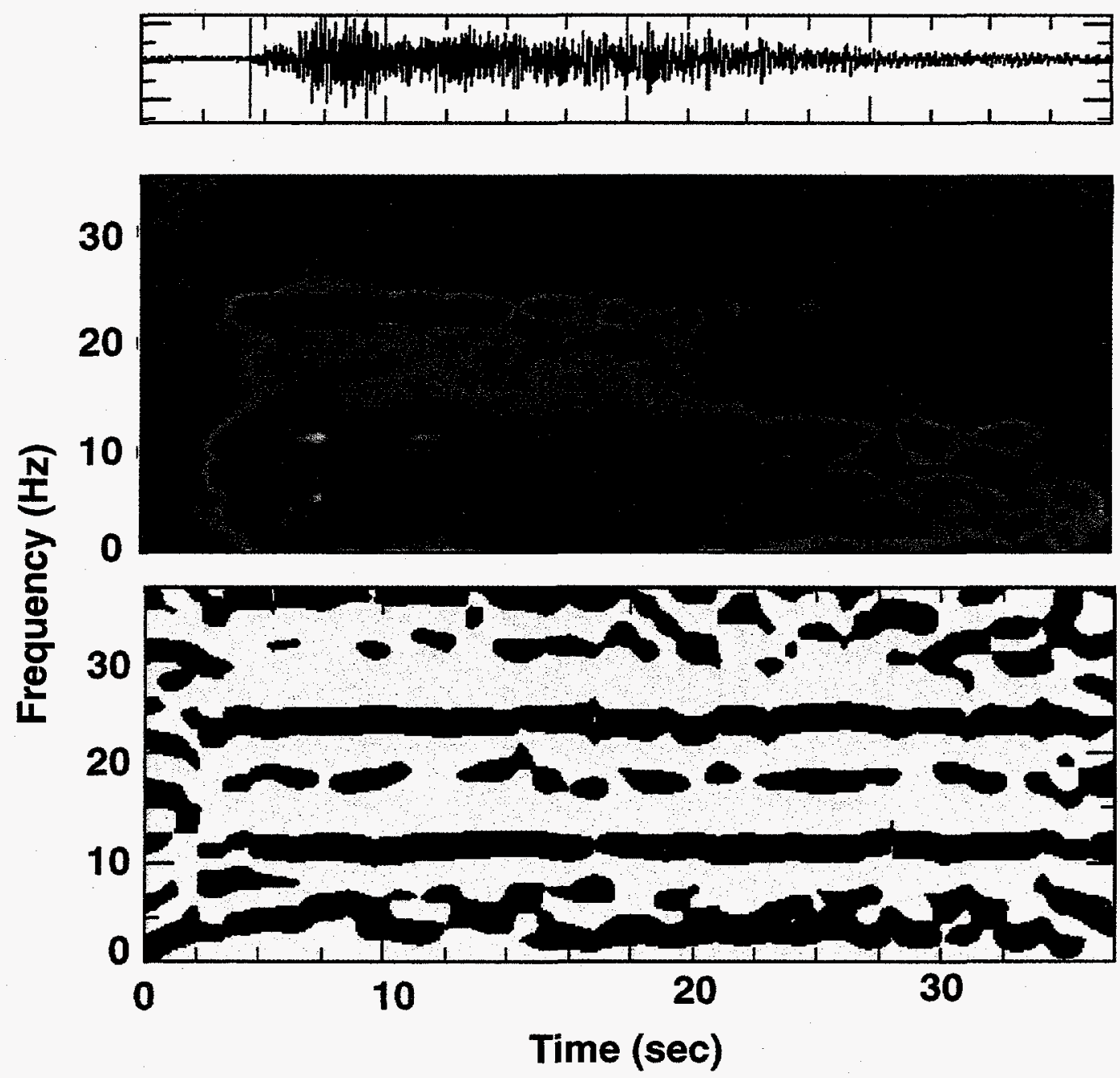

Figure 5. Time series (acceleration), spectrogram, and binary sonogram for event $0420-1$ recorded at ELK.

\subsection{Newmont Gold Company Shot Statistics}

During the time period from April 11 to September 20, 1995, NGC conducted 74 ripple-fired explosions for which we were able to obtain both ground-truth information and ELK seismic data. For 13 of these explosions, a coda magnitude could not be determined because they were followed too closely in time by a subsequent NGC explosion that produced seismic signals which interfered with the measurement of the coda amplitude. Consequently, we have 61 explosions for which both magnitude and ground truth data are available.

Of the 61 explosions, 48 were production shots, 5 were waste shots (so-called because their purpose was to breakup overburden rather than directly produce ore), and 8 were combined shots, in which a waste shot was directly followed or preceded by a 
prod 1 pattern prod 2 patterns prod 3 patterns prod 4 patterns prod 5 patterns prod 6 patterns waste only waste +1 prod waste +2 prod waste +3 prod waste +5 prod

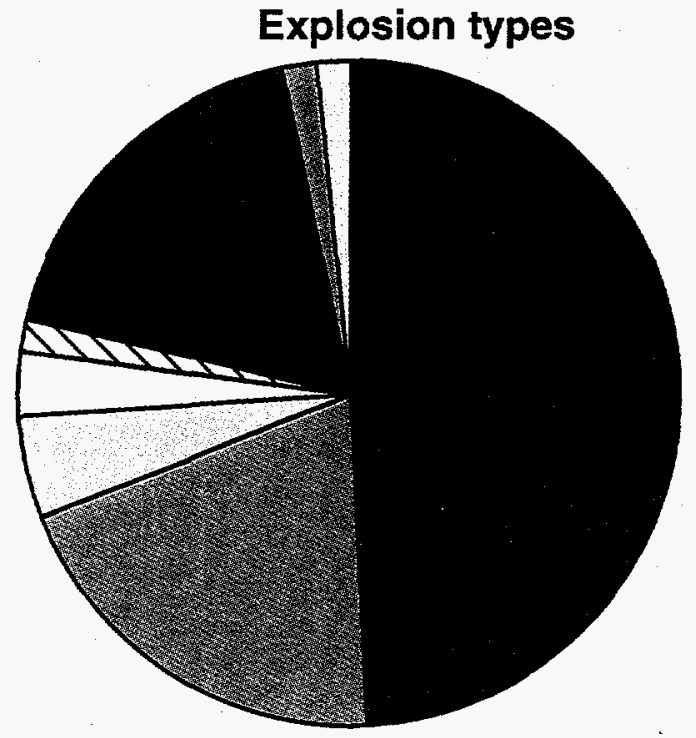

Figure 6. Pie chart diagram showing the various types of shots.

production shot. Thirty four out of the 48 production shots were of multiple-pattern, in which the orientation of the rows or the delays between rows varied within a shot. Figure 6 shows a pie chart diagram of the various types of shots.

The shot elevations ranged from 4,800 to $5,700 \mathrm{ft}$ and were clustered in three distinct groups: from 4,800 to 5,000 ft (26 explosions), from 5,200 to 5,400 ft (22 explosions), and from 5,550 to $5,700 \mathrm{ft}$ (13 explosions). Figure 7 shows the three distinct clusters in a plot of $m_{b}$ as a function of bench height for all 61 shots. Although all of the shots with an $\mathrm{m}_{b}$ greater than 1.5 are clustered in the second group we were unable to find any distinguishing geological features in the second bench that could account for the larger variation in the seismic amplitudes of the shots fired within that bench height.

Four distinct delay devices were used in the ripple fired explosions. The specified delays were $35 \mathrm{~ms}$ ( 1 production shot, 2 waste shots, and 1 combined shot), $50 \mathrm{~ms}$ ( 4 production shots), $65 \mathrm{~ms}$ ( 30 production shots, 2 waste shots, and 6 combined shots), and 100 $\mathrm{ms}$ (17 production shots, 1 waste shot, and 3 combined shots). All the delay devices were manufactured by Ensign-Bickford Co. and were designed to provide an uncertainty of less than $2 \%$ in the delay time. Figure 8 shows the usage of various delays in production, waste, and combined shots and indicates that most of the shots used 65 or 100 ms delays. One production shot used 3 different delays and one used 2 different delays; 3 combined shots used 2 different delays.

The number of holes in the ripple-fired explosion ranged from 43 to 1045, however the weight of explosive per hole had a smaller variation and ranged from 150 to $350 \mathrm{lbs} /$ hole with a mean of 274 and a median of $280 \mathrm{lbs} /$ hole. Figure 9 plots the weight of 


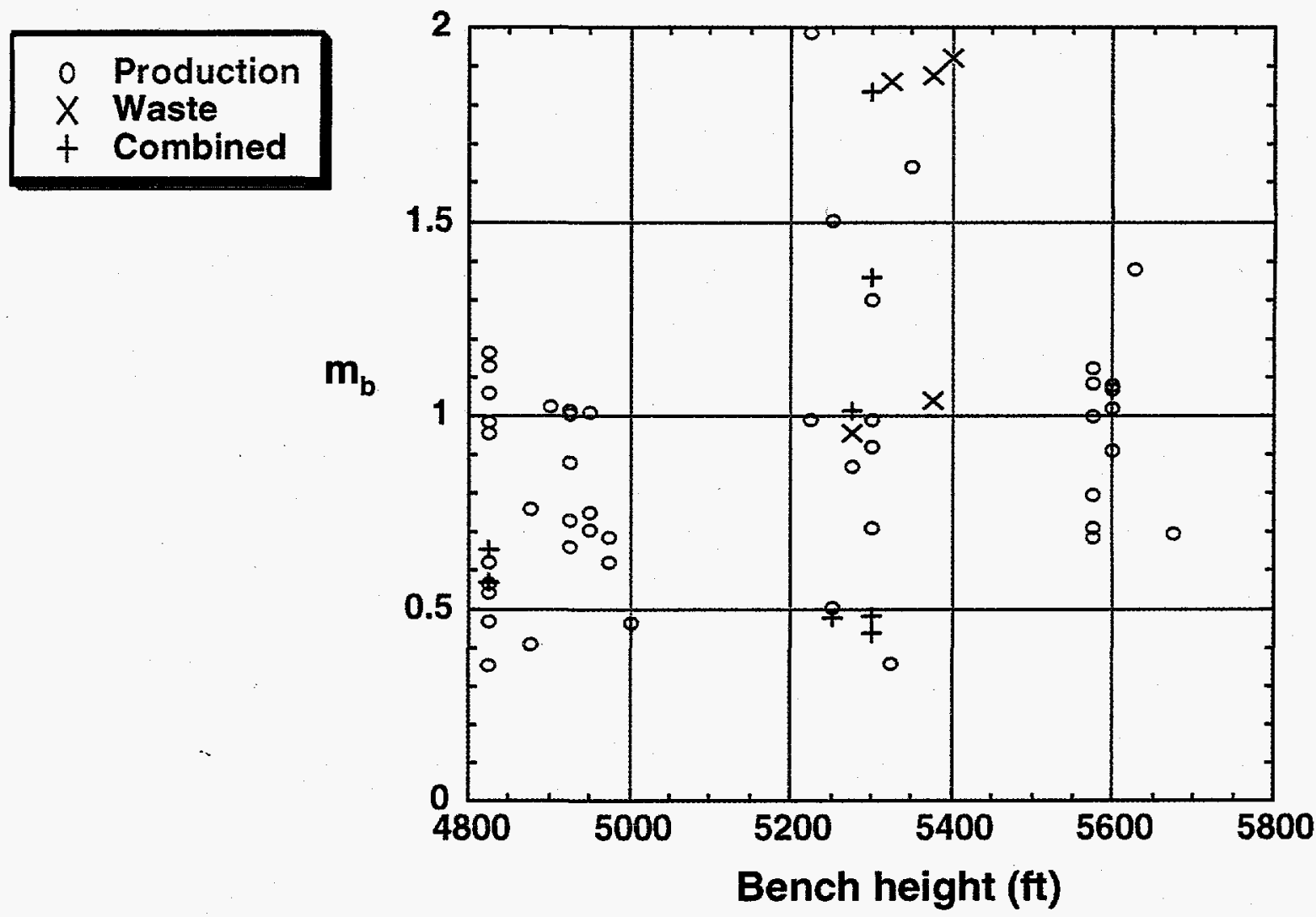

Figure 7. Seismic amplitude as a function of bench height.

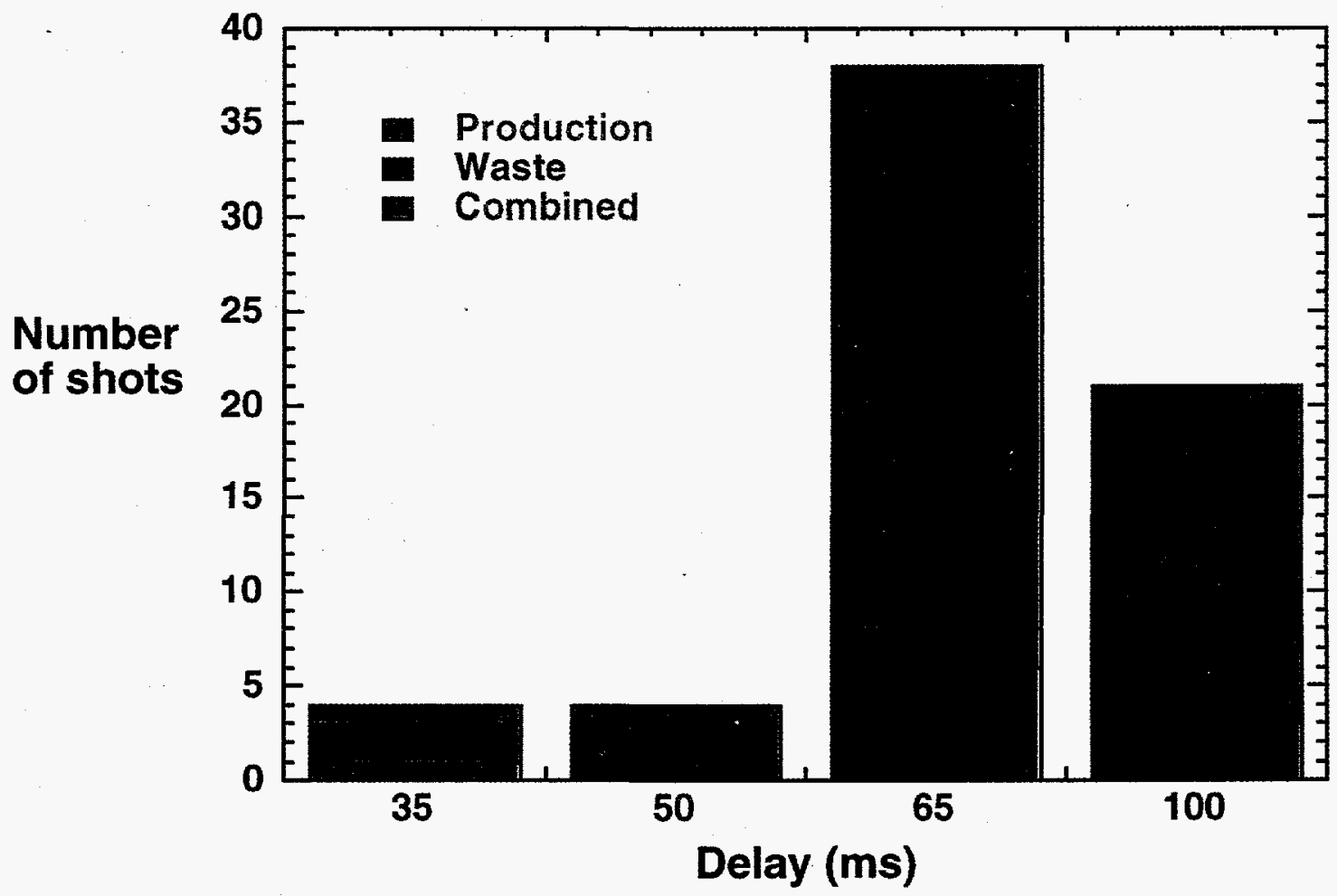

Figure 8. Usage of various delay times in production, waste, and combined shots. 

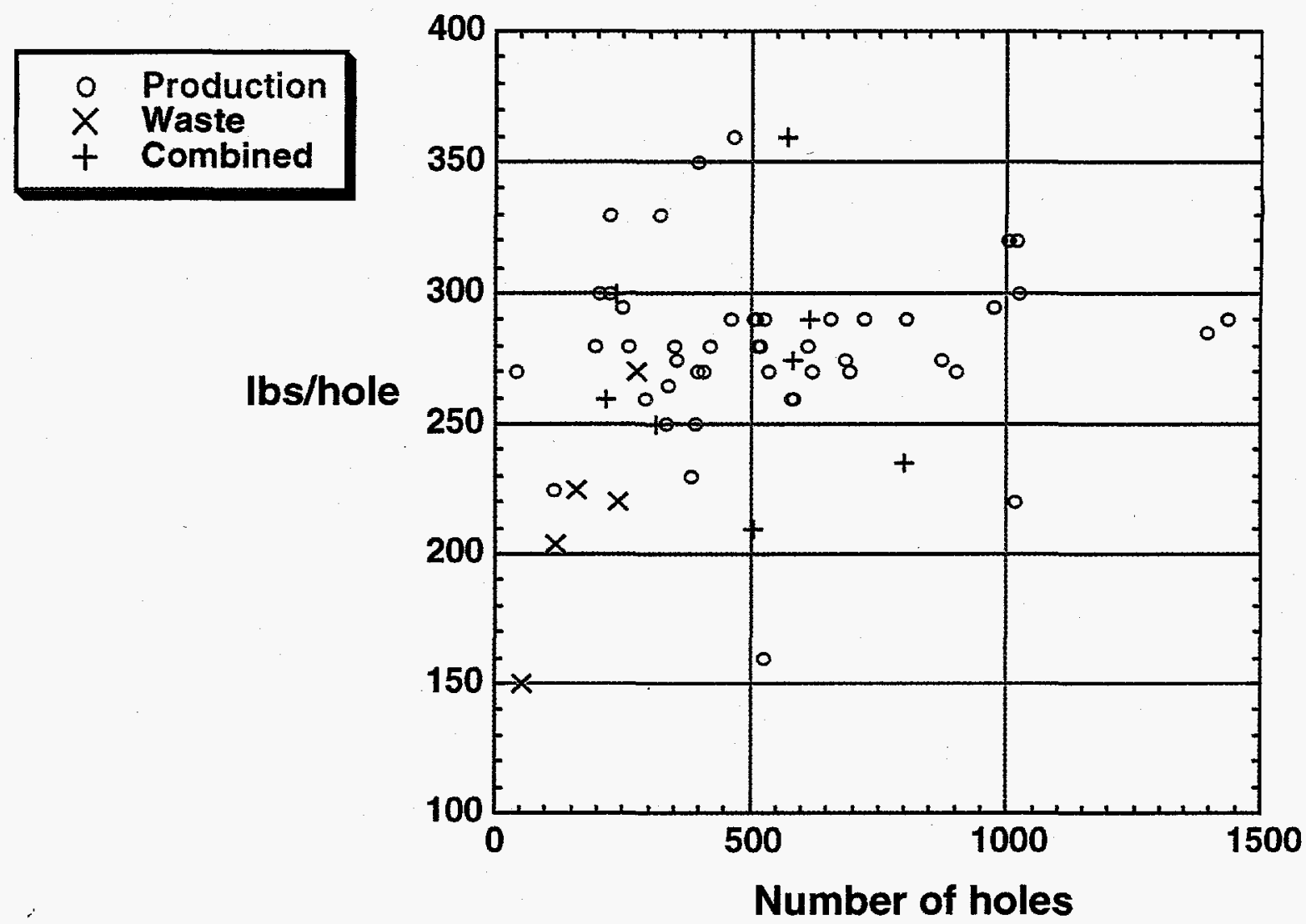

Figure 9. Amount of explosive per hole versus the number of holes for production, waste, and combined shots.

explosive per hole versus the number of holes for production, waste, and combined shots. All the waste shots had fewer than 300 holes.

Our deployment covered a period in which the amount of rainfall, and hence the ground saturation, varied considerably from very wet in the early part of the deployment in Spring to dry towards the end of the deployment in autumn. During this time period there was a nearly uniform distribution in the number of shots with a total yield greater than $0.1 \mathrm{kt}$. Figure 10 shows the total yield for all 61 shots arranged sequentially in chronological order. The nearly horizontal solid line is a linear least squares fit through the data and indicates an approximately constant average yield per shot during this time period. The measured magnitude values, however, indicate a non uniform distribution, in which the largest $m_{b}$ values are all measured in the first half of the deployment when the ground was wet. Figure 11 shows the magnitude values for all 61 shots arranged sequentially in chronological order. All the $\mathrm{m}_{\mathrm{b}}$ values larger than 1.5 were measured during the first half of the deployment. The negative slope of the least squares fit through the data suggests smaller signals as the ground dried up and coupling between the explosive energy and the rock decreased. The available data, however, 

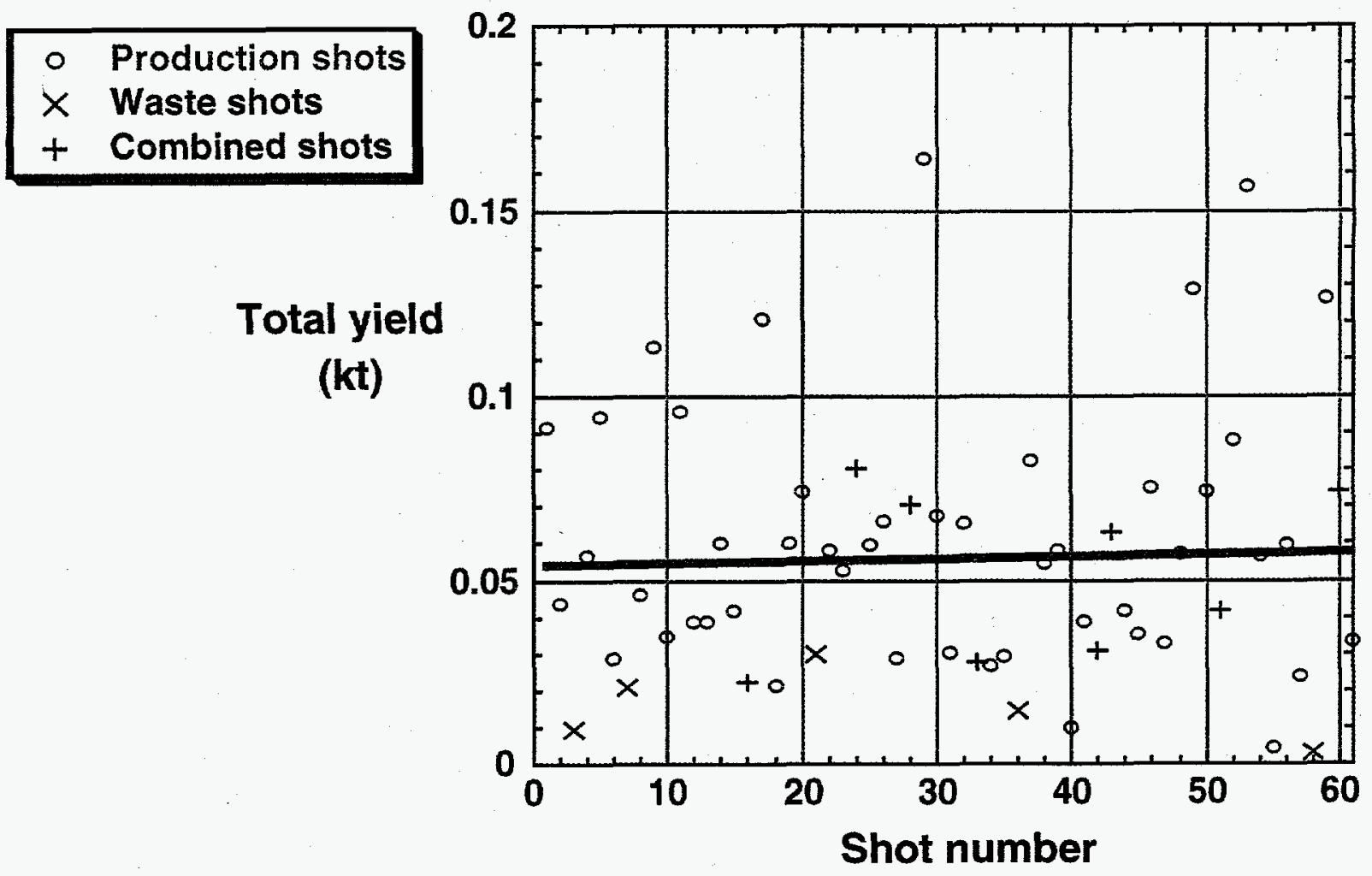

Figure 10. Total yield for the 61 mine explosions arranged in chronological order.
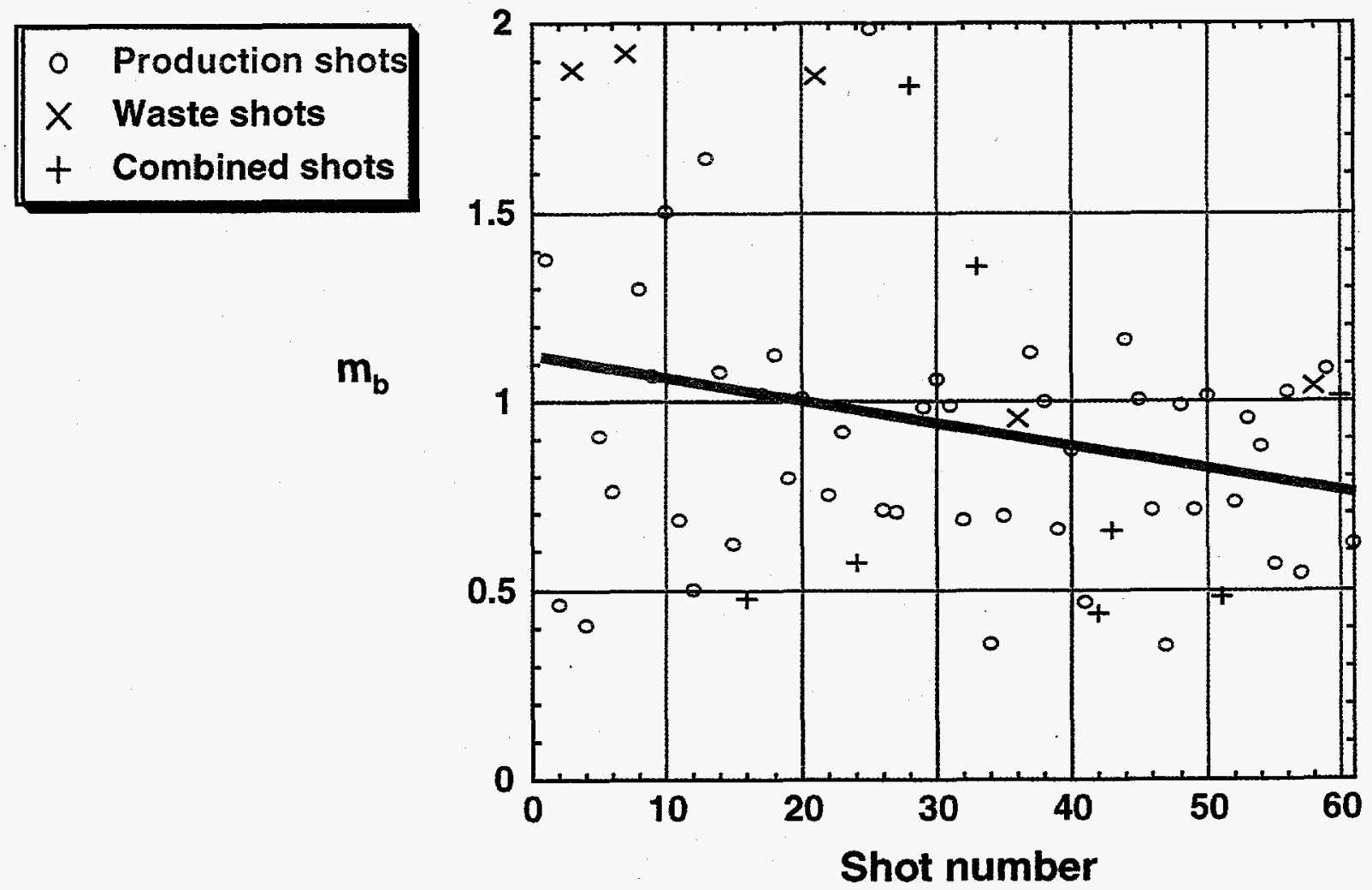

Figure 11. Seismic magnitude for the 61 mine explosions arranged in chronological order. 


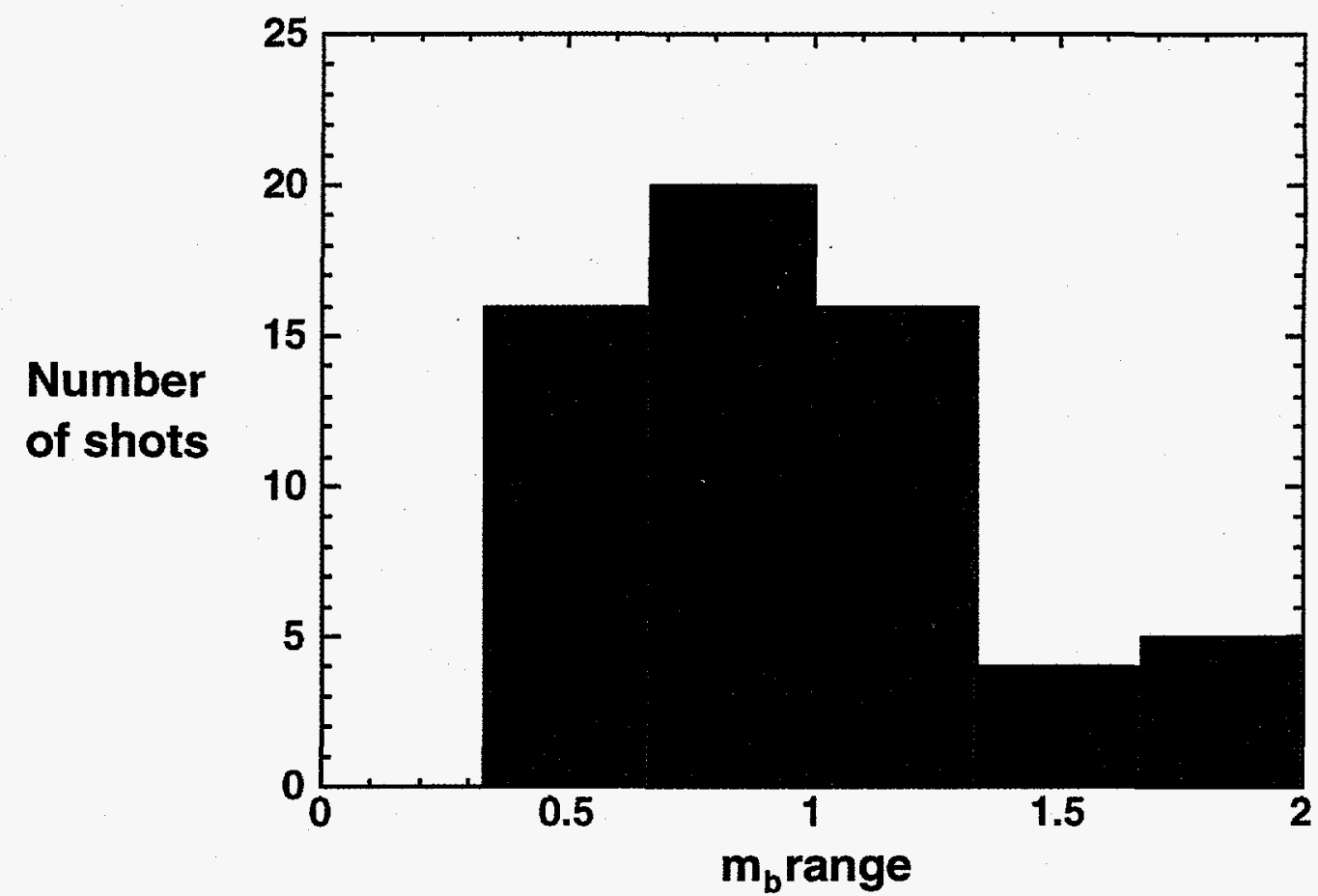

Figure 12. Histogram showing the number of shots within each of $5 \mathrm{mb}$ ranges.

exhibit considerable scatter and do not conclusively prove a causal relationship between ground saturation and large seismic amplitudes. To confirm or deny such a hypothesis would require data collection over several rainy seasons. A preliminary investigation of seismic amplitudes from other mines in the Nevada area did not indicate a similar trend.

The NGC shots that produced seismic signals with $m_{b}$ greater than 1.5 included 3 waste shots, 3 production shots, and 1 combined shot. Since there were only 5 waste shots in the total of 61 shots considered, it appears that the waste shots are more likely to produce higher magnitude values. Figure 12 is a histogram of the magnitude range and suggests a nearly bimodal distribution, in which about $10 \%$ of the shots are located within the higher peak.

\subsection{Effect of Shot Parameters on Magnitude}

The relationship between the seismic magnitudes of the Carlin mining explosions and various explosion parameters is of some interest since, for underground nuclear explosions, there are well established correlations between magnitude and yield. We have searched for similar relations between magnitude and total yield, yield per unit time, number of delays, and total shot duration. Figure 13 shows magnitude as a function of total yield for production, waste, and combined shots. The least squares linear fit (shown in red) indicates no correlation in this limited range. On the same graph, we also plot the fit determined for the Nevada Test Site by Vergino and Mensing [1990]. Note 


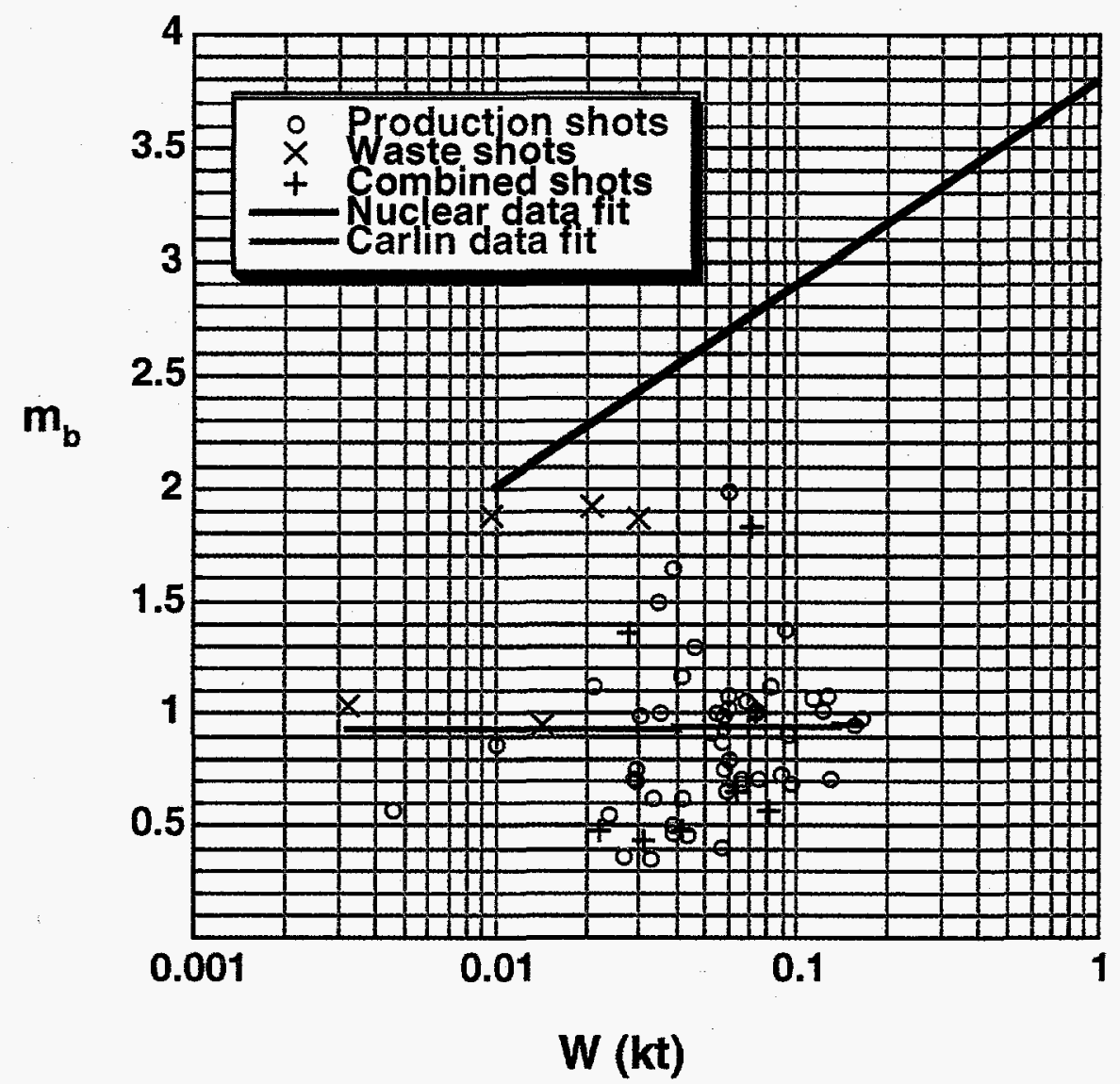

Figure 13. Seismic amplitude as a function of total yield for production, waste, and combined shots.

that with the present method, which uses NTS explosion data to calibrate the magnitude scale, all NGC explosions fall below the extrapolated Vergino and Mensing fit. Figure 14 shows the relationship between magnitude and energy release rate (total yield divided by the total time). Although the data exhibit large scatter, the correlation coefficient was calculated to be 0.32 . In Figures 15 and 16 we plot magnitude as a function of the number of delays and the total shot duration and conclude that there is no correlation between the observed $m_{b}$ values and these shot parameters for NGC shots.

It may be that some nonlinear comb $b_{\Downarrow}$ ation correlates better with magnitude than do the individual shot parameters. However, even if a unique relationship exists, this would be of very limited use since these parameters would not be very well known to seismic monitors. In the next section, we consider characteristics of the seismic signals that might be useful for discrimination

\subsection{Discriminant Performance}

We used our database of earthquakes and explosions to assess the performance of two methods for discriminating between ripple-fired explosions and earthquakes. In 

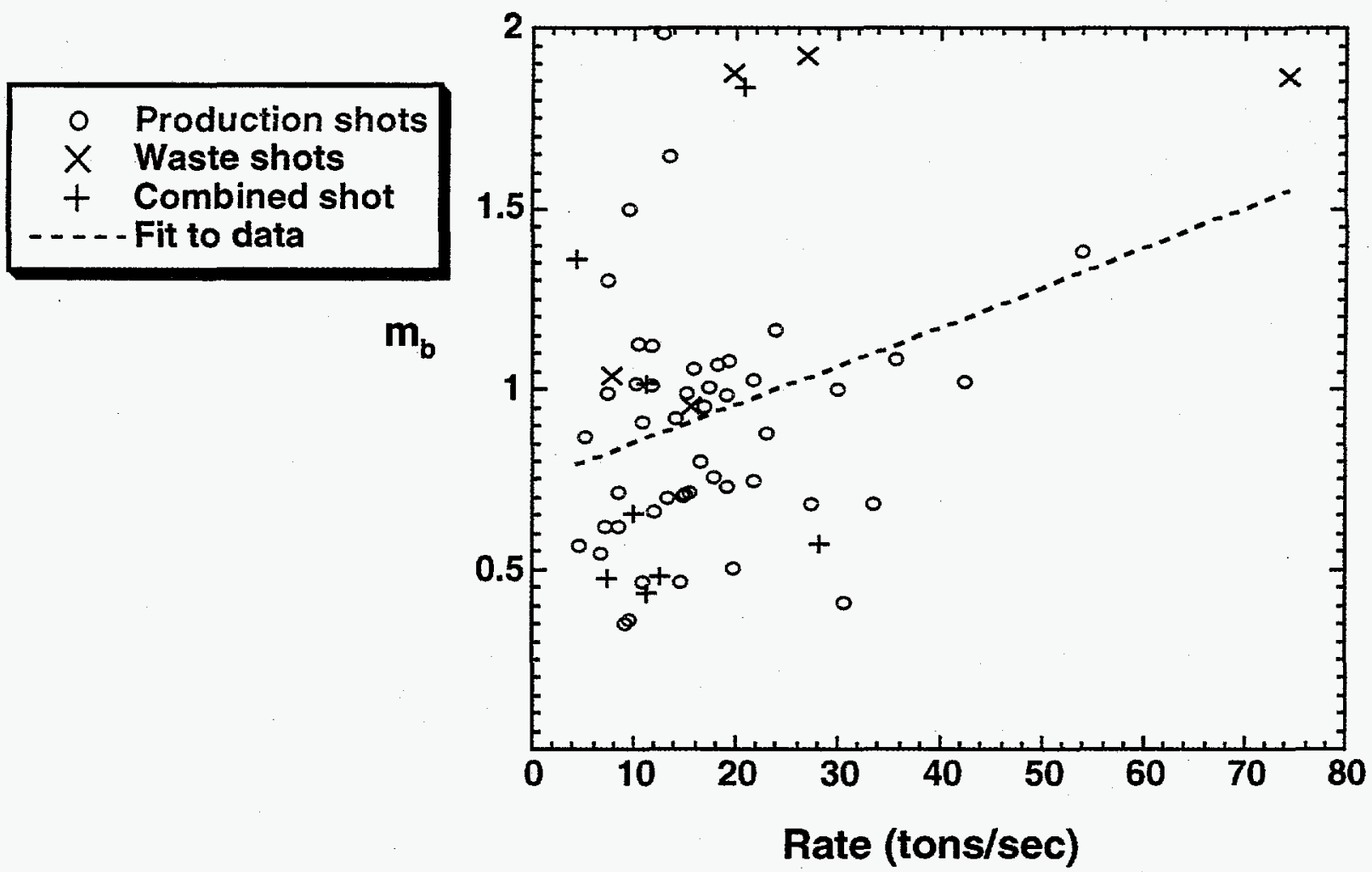

Figure 14. Seismic amplitude as a function of energy release rate for production, waste, and combined shots.

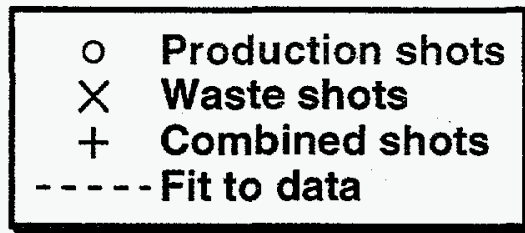

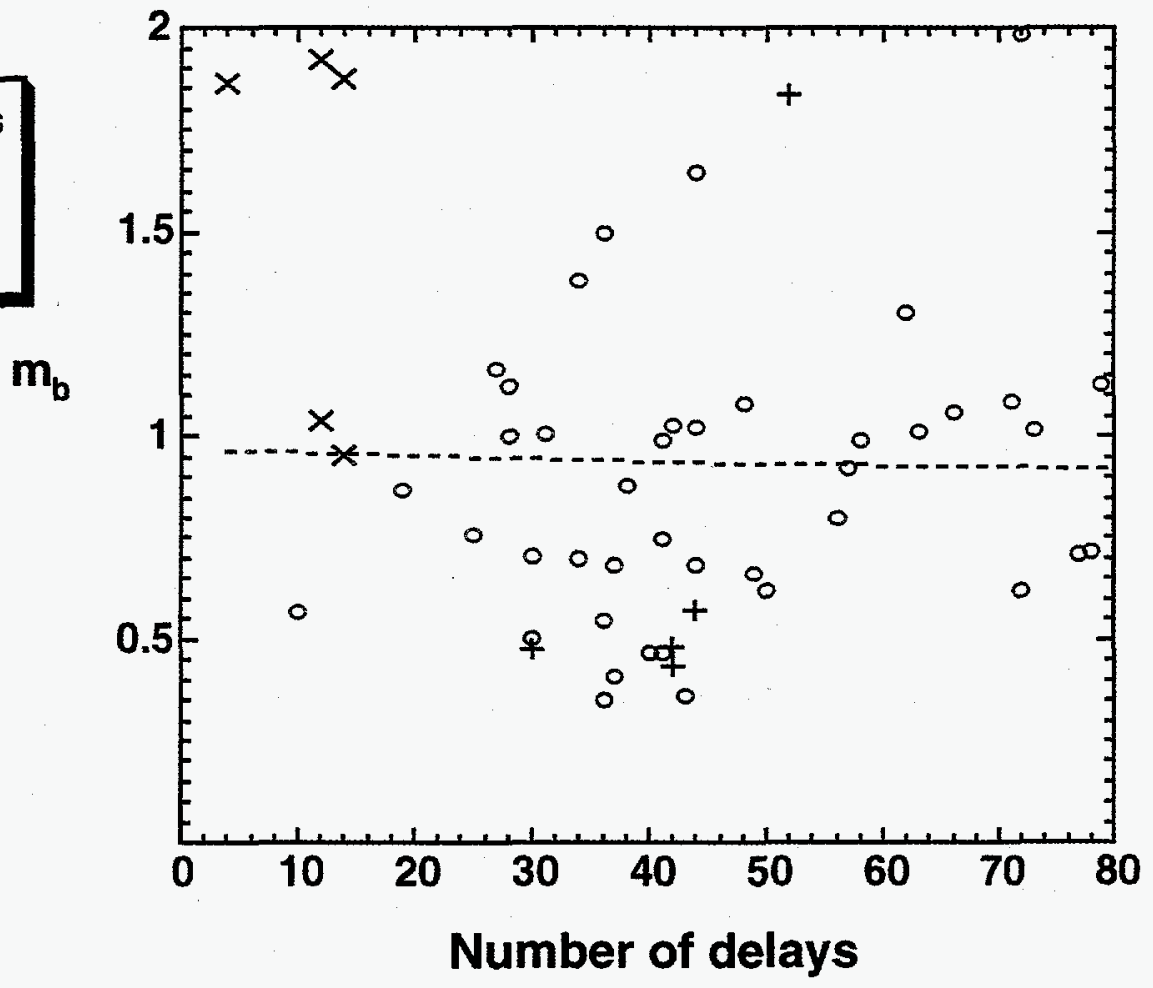

Figure 15. Seismic amplitude as a function of number of delays for production, waste, and combined shots. 


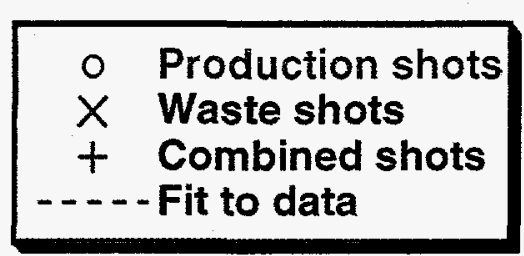

$m_{b}$

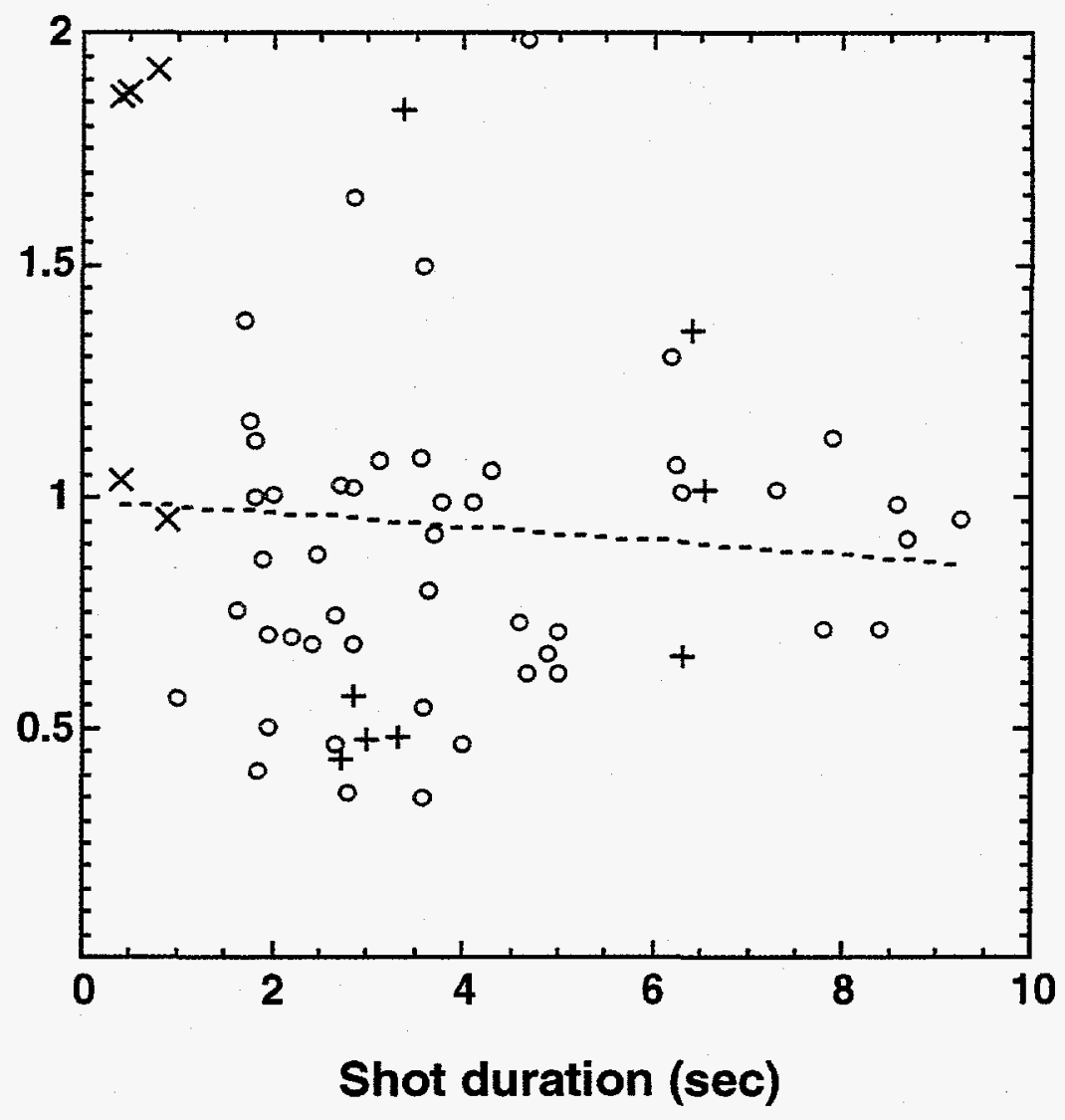

Figure 16. Seismic amplitude as a function of total shot duration for production, waste, and combined shots.

section 3.5 .2 we attempt to address the question of discrimination between concentrated and ripple-fired explosions.

The two methods are based on the time-independent spectral features produced by the ripple-fired source. Hedlin et al . (1990) computes a 2-D FFT of the spectrogram of the coda of the event of interest. The 2-D FFT has units of quefrency (inverse frequency) on one axis and time-frequency on the other axis. The amplitude as a function of quefrency at a time-frequency of zero is the time-independent portion of the 2-D FFT because it represents a signal with an infinite duration. The peak amplitude of this function is the value used as the "discriminant".

Wüster (1990) integrates the binary sonogram at each frequency, in time windows representing both signal and pre-event noise, to identify the time-independent features. The resulting integrals are normalized; i.e., a continuous band across all time at a certain frequency produces a value of 1.0. Peaks in the signal integral that exceed a threshold $(0.75)$ and are not present in the noise signify a ripple-fired explosion.

We used a modified Hedlin et al . (1990) method in that we employed binary sono- 
grams instead of spectrograms, and we used maximum-entropy-method power spectra of the integrals computed for the Wüster method to obtain the time-independent amplitude functions.

\subsubsection{Performance with our Explosion-Earthquake Database}

Figures 17 and 18 show the amplitudes of the discriminant in each case, plotted as a function of $m_{b}$. These plots show that both discriminants are able to separate the earthquake and ripple-fired explosion populations reasonably well, although a few events ( $10 \%$ of each type) are misclassified.

\subsubsection{Simultaneous Concentrated and Ripple-Fired Explosions}

In order to evaluate the various discriminants, we modeled a scenario in which a concentrated nuclear explosion is caused to occur during a ripple fired mine explosion. Previous investigation by Smith (1993) indicated that a large, deeply buried explosion dominates the waveform signature if it contains more than 5 to $15 \%$ of the total explosive in the mining blast. For the concentrated blast in this investigation, we used the seismic signal from the NPE explosion at a station that was part of the Southern Sierra Nevada Continental Dynamics Project (Keller et al.., 1994) and was located $85.4 \mathrm{~km}$ from ground zero.

To simulate a nuclear shot of yield one kiloton decoupled by a factor of 100 (nominally considered to be the maximum possible decoupling), we divided the amplitude of the velocity time-history signal from the NPE explosion by 100 and added that signal to 3 representative mine explosions designated 0414-2, 0607, and 0726-2. The first explosion was a waste shot with total yield of under 10 tons, the second a production shot with a single pattern (total yield of 39 tons) and the third a production shot with 4 different firing patterns (total yield of 60 tons). We recalculated the $\mathrm{m}_{\mathrm{b}}$ values after adding the simulated decoupled nuclear shot and found that it remained practically unchanged. The table below summarizes the results:

Magnitude

$$
\text { before summing after summing }
$$

$\begin{array}{lll}0414 \_2 & 1.88 & 1.87 \\ 0607 & 1.64 & 1.70 \\ 0726 \_2 & 1.98 & 1.97\end{array}$

Thus, based on magnitude alone, the decoupled nuclear shot could not be detected.

Next we applied the Cepstrum (Hedlin) discriminant to all the shots (a total of 70) for which we had seismic data regardless of whether or not we were able to obtain an $\mathrm{m}_{\mathrm{b}}$ 


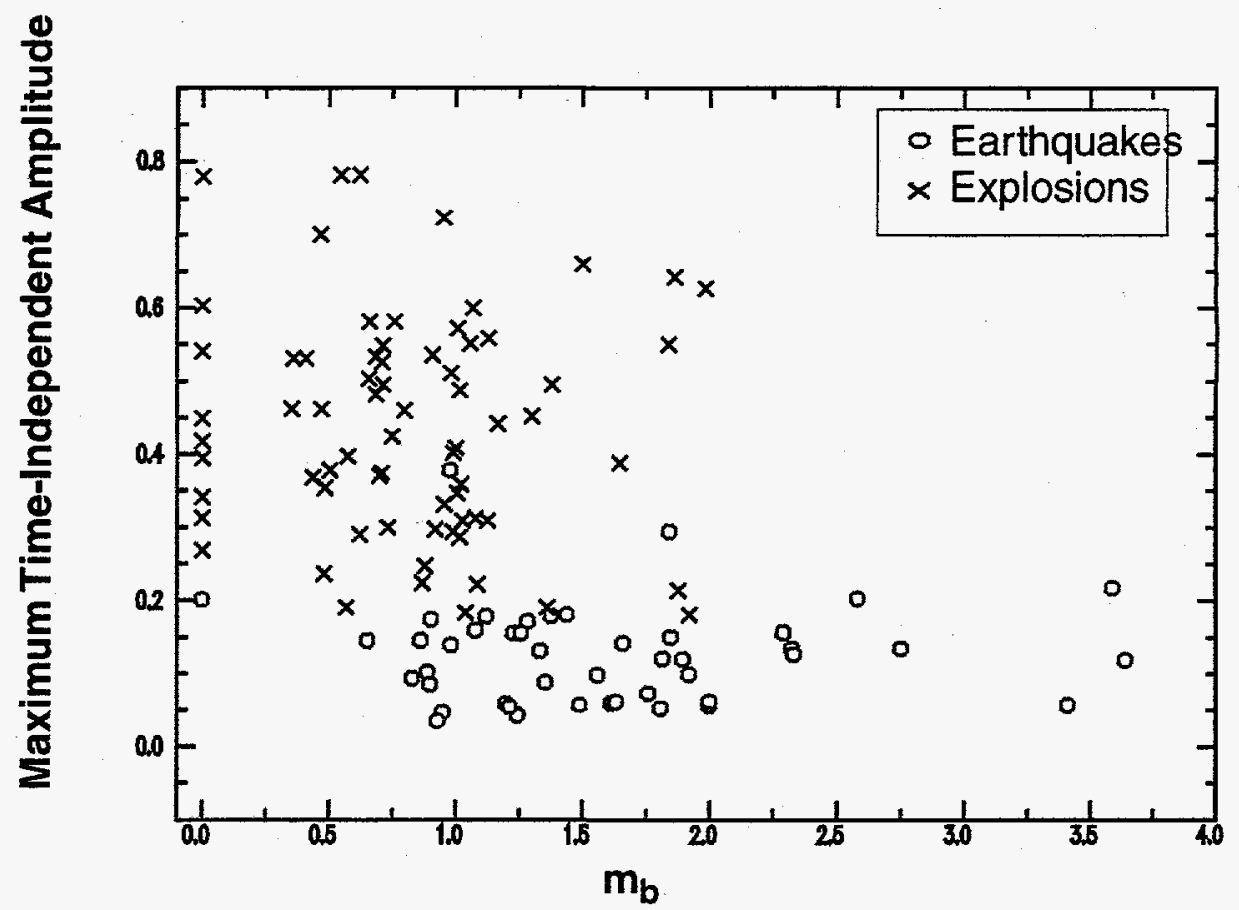

Figure 17. Summary of results for the discrimination method of Hedlin et al. (1990). A zero-timefrequency spectrum was computed from the binary sonograms of the earthquakes and explosions. The plot shows the maximum value of this function for each event, plotted as a function of magnitude. A magnitude of 0.0 indicates that a coda magnitude could not be measured for that event.

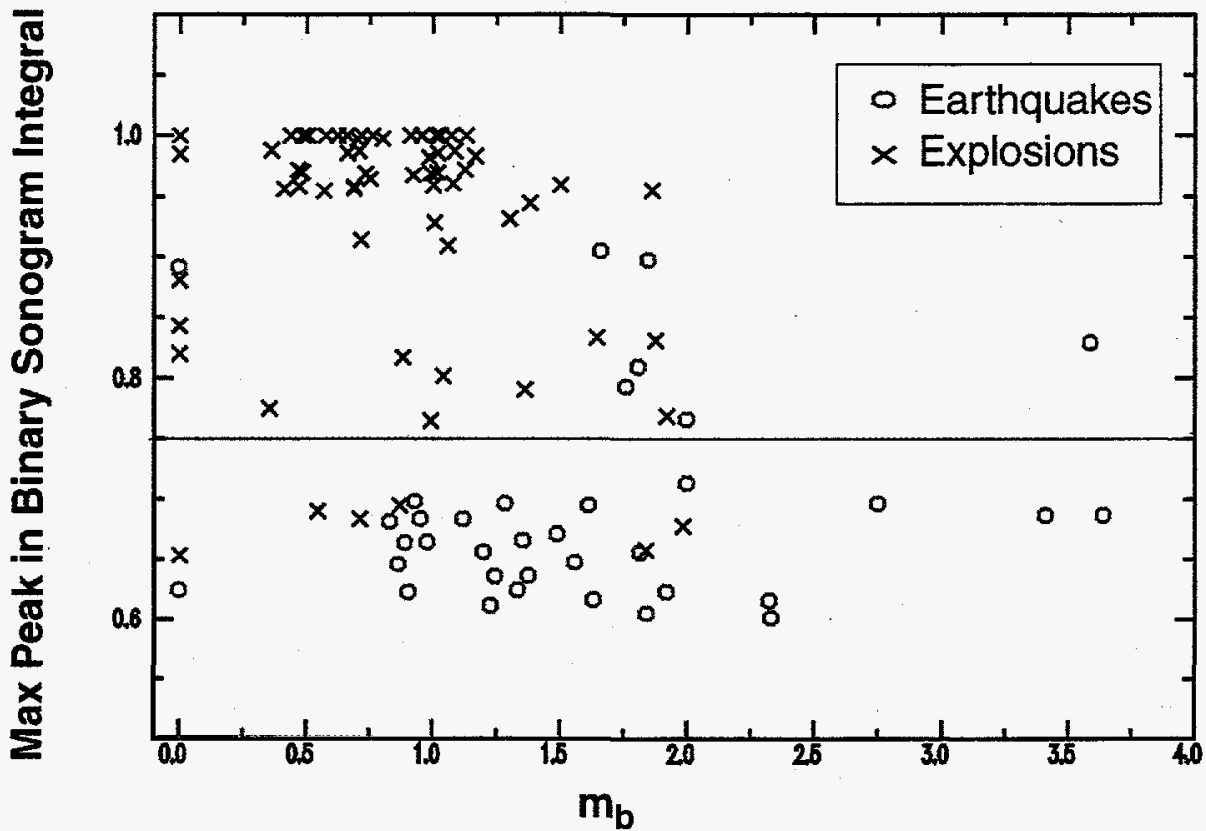

Figure 18. Summary of results for the discrimination method of Wüster (1990). Binary sonograms of the earthquakes and explosions were integrated and normalized at each frequency to form a function with values between 0 and 1 . The plot shows the maximum value of this function for each event plotted as a function of magnitude A magnitude of 0.0 indicates that a coda magnitude could not be measured for that event. The decision threshold proposed by Wüster $(0.75)$ is drawn as the horizontal line. 
value. We found that if we used a decision threshold of 0.17 , all 70 explosions were classified as ripple-fired. After adding the concentrated source 37 explosions remained classified as ripple fired and 33 explosions were classified as "not ripple fired".

When we used the Wüster discriminant, 45 explosions passed the signal to noise test both before and after adding the concentrated source. Using a decision threshold of 0.75 , 39 were classified as ripple fired and 6 were classified as not. After adding the concentrated source, 23 of the explosions previously classified as ripple fired remained classified as ripple fired. Sixteen of the explosions previously classified as ripple fired were classified as not ripple fired.

InTable A2 in the appendix, we summarize the results of all the tests and show the sonograms for the various mine explosions.

\subsection{Summary and Implications for the Verification of a CTBT}

We conducted an investigation of surface mining blasts in metamorphic rock in the Carlin, NV area, for which extensive ground truth was obtained. A total of 61 blasts were analysed during the time period from April 11, 1995 to September 20, 1995. Of the 61 explosions, 48 were production shots, 5 were waste shots (meaning that their purpose was to break up overburden rather than directly produce ore) and 8 were combined shots in which a waste shot was directly followed or preceded by a production shot. The blasts that produced the largest seismic amplitude included 3 waste shots, 3 production shots, and 1 combined shot, and were all fired during a rainy period in the first half of the deployment at a bench height between 5,200 to 5,400 ft. We found no correlation between the total yield of the shots and the coda amplitude measured at the ELK station, $80 \mathrm{~km}$ away. Attempts to correlate other shot parameters with seismic magnitude were largely unsuccessful.

It was found that methods that rely on time-independent spectral modulation of the seismic data discriminate commercial blasting activity from nearby earthquakes, although these methods appear to misclassify approximately $10 \%$ of each population.

A potential evader might attempt to use commercial blasting activity to conceal underground nuclear testing. Two tactics have been suggested in the past. The first is to simultaneously detonate the nuclear explosion and a conventional ripple-fired quarry blast in such a way that the seismic signal from the explosion would be indistinguishable from that of quarry blast alone. We tested this idea by superimposing the signal from a fully decoupled 1-kt explosion (simulated by scaling the data from the kiloton-level Non-Proliferation Experiment) on those of several Carlin blasts. It was found that the spectral discriminants were generally capable of identifying the combined signal as "not ripple-fired" when the quarry blast itself was found to be "ripple-fired". When the quarry blast itself was not ripple fired, however, the discriminants perforce failed. 
The second tactic is based on this idea. In this scheme, the evader begins mining in a remote area and specifically eschews ripple-fired practice to establish a pattern of blasting with near-zero delays. This invites requests for an on-site inspection which, of course, reveals no evidence of nuclear testing and thereby establishes credibility that bona fide mining is indeed taking place. Once this is done, cavity decoupled nuclear explosions can be periodically substituted for the routine blasting. Using this tactic, nuclear explosions with yields up to $10 \mathrm{kt}$, or even more, might be performed. The main limitation would be the ability to locate and/or construct underground cavities of the required size and shape that would remain stable under explosive loading. Such cavities are known to exist in salt domes, but have not been fully evaluated in other media. Present indications are that the seismic signals from the decoupled explosion would be indistinguishable from the surface blasting activity. Testing of the concept in local geologic media could be accomplished with chemical explosives employed as a surrogate for the nuclear explosive, thereby minimizing the risk of a cavity collapse and potential loss of containment of fission products.

\subsection{Acknowledgments}

A special thanks is due the Newmont Gold Company (NGC) for their support and extended hospitality, and for their provision of ground truth data; we are grateful, in particular, to Jeff Mattern, Kurt Kriss, Trent Embry, and Ali Soltani. LLNL engineering and instrumentation support were provided by Don Rock, Pat Lewis, and Sierra Boyd. François Heuzé coordinated the arrangements for the deployment. This work was performed under the auspices of the U. S. Department of Energy by the Lawrence Livermore National Laboratory under contract No. W-7405-ENG-48. The DOE Program Manager in the Office of Research and Development (NN-20) was Ms. Leslie A. Casey.

\section{References}

Chapman, M. C., G. A. Bollinger, and M. S. Sibol (1992). Modeling delay-fired explosion spectra at regional distances, Bull. Seism. Soc. Am. 82, 2430-2447.

Denny, M. D., editor, (1994) Proceedings of the Symposium on The Non-Proliferation Experiment (NPE): Results and Implications for Test Ban Treaties

Denny, M. D., S. R. Taylor, and E. S. Vergino (1987). Investigations of $\mathrm{mb}$ and $\mathrm{ms}$ formulas for the Western United States and their impact on the $\mathrm{ms} / \mathrm{mb}$ discriminant, Bull. Seism. Soc. Am. 77 987-995.

Hedlin, M. A. H., J. B. Minster, and J. A. Orcutt (1989). The time-frequency characteristics of quarry blasts and calibration explosions recorded in Kazakhstan, USSR, Geophys. J. Int. 99, 109-121.

Hedlin, M. A. H., J. B. Minster, and J. A. Orcutt (1990). An automatic means to discriminate between earthquakes and quarry blasts, Bull. Seism. Soc. Am. 80B, 2143-2160. 
Jarpe, S.P., P. Goldstein, B. Moran, and L.A. Glenn (1995). Preliminary Report on the Implications of Mining Practices in an Open-Pit Gold Mine for Monitoring of a Comprehensive Test Ban Treaty, Lawrence Livermore National Laboratory publication UCRL-ID-121228.

Keller, G. R., P. E. Malin, and S. D. Ruppert (1994). Southern Sierra Nevada Continental Dynamics Project: 1993 field observations of the NPE, in Symposium on the Non-Proliferation Experiment: Results and Implications for Test Ban Treaties, M. D. Denny (editor), Lawrence Livermore National Laboratory publication CONF-9404100, 6-277.

Kim, W. Y., D. W. Simpson, and P. G. Richards (1994) High-frequency spectra of regional phases from earthquakes and chemical explosions, Bull. Seism. Soc. Am. 84, 13651386.

Mayeda, K. and W. Walter (1995), Moment, Energy, Stress Drop and Spectra of Western U.S. Earthquakes from Regional Coda Envelopes, Journal of Geophysical Research, in press.

Mayeda, K. (1993), mb(LgCoda): a stable single station estimator of magnitude, Bull. Seism. Soc. Am. 83, 851-861.

Richards, P. G. (1994). Blasting activity of the mining industry in the United States, in Symposium on the Non-Proliferation Experiment: Results and Implications for Test Ban Treaties, M. D. Denny (editor), Lawrence Livermore National Laboratory publication CONF-9404100, 2-16.

Smith, A. T. (1989). High-frequency seismic observations and models of chemical explosions: implications for the discrimination of ripple-fired mining blasts, Bull. Seism. Soc. Am. 79, 1089-1110.

Smith, A. T. (1993). Discrimination of explosions from simultaneous mining blasts, Bull. Seism. Soc. Am. 83, 160-179.

Stump, B. W. and S. K. Reamer (1988). Temporal and spatial source effects from nearsurface explosions, 10 the Annual AFGL/DARPA Seismic Research Symposium, Fallbrook, CA.

Stump, B. W. and R. E. Reinke (1988). Experimental confirmation of superposition from small-scale explosions, Bull. Seism. Soc. Am. 78, 1059-1073.

Stump, B. W. and D. C. Pearson (1995). LANL source geometry quick look report, EES395-175, June 9, 1995

Vergino, E. S. and R. W. Mensing (1990). Yield estimation using regional $m_{b}(\mathrm{Pn})$, Bull. Seism. Soc. Am. 80, 656-674.

Walter, W. R., K. Mayeda, and H. J. Patton (1994). Regional seismic observations of the Non-Proliferation Experiment at the Livermore NTS network, in Symposium on the Non-Proliferation Experiment: Results and Implications for Test Ban Treaties, M. D. Denny (editor), Lawrence Livermore National Laboratory publication CONF9404100, 6-193.

Wüster, J. (1990). Discrimination of chemical explosions and earthquakes in central Europe--a case study, Bull. Seism. Soc. Am. 83, 1184-1212. 


\section{Appendix A}

Table A1

\begin{tabular}{|l|l|l|l|l|l|l|l|l|l|}
\hline $\begin{array}{c}\text { LLNL } \\
\text { ID }\end{array}$ & $\mathrm{m}_{\mathrm{b}}$ & $\begin{array}{c}\text { Bench } \\
\text { height } \\
\text { (ft) }\end{array}$ & $\begin{array}{c}\text { Delay } \\
\mathrm{ms}\end{array}$ & $\begin{array}{c}\text { \#of } \\
\text { holes }\end{array}$ & $\begin{array}{c}\text { lbs/ } \\
\text { hole }\end{array}$ & $\begin{array}{c}\text { \#of } \\
\text { delay } \\
\mathrm{s}\end{array}$ & $\begin{array}{c}\text { yield/ } \\
\text { time } \\
\text { (ton/ } \\
\text { sec) }\end{array}$ & $\begin{array}{c}\text { Total yield } \\
\text { (kt) }\end{array}$ & $\begin{array}{c}\text { Durat } \\
\text { ion } \\
\text { (sec) }\end{array}$ \\
\hline \hline 0413 & 1.37 & 5625 & 50 & 802 & 290 & 34 & 53.9 & 0.091778 & 1.70 \\
\hline $0414-1$ & 0.469 & 5000 & 100 & 400 & 270 & 40 & 10.4 & 0.043577 & 4.00 \\
\hline $0414-2$ & 1.87 & 5375 & 35 & 120 & 204 & 14 & 19.7 & 0.009660 & 0.400 \\
\hline 0418 & 0.400 & 4870 & 50 & 510 & 280 & 30 & 30.8 & 0.056903 & 1.80 \\
\hline 0427 & 0.917 & 5600 & 100 & 870 & 270 & 80 & 10.7 & 0.094627 & 8.70 \\
\hline $0505-1$ & 0.757 & 4870 & 65 & 250 & 290 & 20 & 17.9 & 0.029102 & 1.60 \\
\hline $0505-2$ & 1.91 & 5400 & 65 & 242 & 220 & 12 & 26.9 & 0.021009 & 0.780 \\
\hline $0509-2$ & 1.30 & 5300 & 100 & 420 & 280 & 62 & 7.48 & 0.046406 & 6.20 \\
\hline 0512 & 1.06 & 5600 & 65 & 975 & 295 & 96 & 18.1 & 0.11350 & 6.240 \\
\hline $0516-3$ & 1.50 & 5250 & 100 & 383 & 230 & 36 & 9.65 & 0.034761 & 3.60 \\
\hline 0523 & 0.680 & 4970 & 65 & 900 & 270 & 40 & 33.8 & 0.095890 & 2.80 \\
\hline 0525 & 0.505 & 5250 & 65 & 390 & 250 & 30 & 19.2 & 0.038672 & 1.90 \\
\hline 0607 & 1.64 & 5350 & 65 & 350 & 280 & 44 & 13.5 & 0.038672 & 2.86 \\
\hline 0608 & 1.07 & 5600 & 65 & 527 & 290 & 48 & 19.3 & 0.060308 & 3.12 \\
\hline $0627-1$ & 0.626 & 4970 & 100 & 390 & 270 & 50 & 8.37 & 0.041979 & 5.00 \\
\hline $0627-2$ & 0.477 & 5250 & 100 & 210 & 260 & 30 & 7.43 & 0.022264 & 3.00 \\
\hline 0628 & 1.02 & 5600 & 65 & 102 & 300 & 44 & 42.3 & 0.12111 & 2.86 \\
\hline 0707 & 1.12 & 5575 & 65 & 194 & 280 & 28 & 11.7 & 0.021435 & 1.82 \\
\hline 0714 & 0.799 & 5570 & 65 & 520 & 290 & 50 & 16.0 & 0.060423 & 3.60 \\
\hline $0718-1$ & 1.01 & 4950 & 100 & 695 & 270 & 63 & 11.7 & 0.074049 & 6.30 \\
\hline $0718-2$ & 1.86 & 5325 & 100 & 279 & 270 & 4 & 74.3 & 0.029726 & 0.400 \\
\hline $0724-1$ & 0.747 & 4950 & 65 & 500 & 290 & 40 & 21.1 & 0.058020 & 2.60 \\
\hline $0724-2$ & 0.920 & 5300 & 65 & 450 & 290 & 50 & 14.7 & 0.052527 & 3.70 \\
\hline $0726-1$ & 0.577 & 4820 & 65 & 560 & 360 & 40 & 28.3 & 0.080832 & 2.80 \\
\hline
\end{tabular}


Table A1

\begin{tabular}{|l|l|l|l|l|l|l|l|l|l|}
\hline $\begin{array}{c}\text { LLNL } \\
\text { ID }\end{array}$ & $\mathrm{m}_{\mathrm{b}}$ & $\begin{array}{c}\text { Bench } \\
\text { height } \\
\text { (ft) }\end{array}$ & $\begin{array}{c}\text { Delay } \\
\mathrm{ms}\end{array}$ & $\begin{array}{c}\text { \#of } \\
\text { holes }\end{array}$ & $\begin{array}{c}\text { lbs/ } \\
\text { hole }\end{array}$ & $\begin{array}{c}\text { \#of } \\
\text { delay } \\
\mathrm{s}\end{array}$ & $\begin{array}{c}\text { yield/ } \\
\text { time } \\
\text { (ton/ } \\
\text { sec) }\end{array}$ & $\begin{array}{c}\text { Total yield } \\
\text { (kt) }\end{array}$ & $\begin{array}{c}\text { Durat } \\
\text { ion } \\
(\mathrm{sec})\end{array}$ \\
\hline \hline $0726-2$ & 1.98 & 5225 & 65 & 583 & 260 & 72 & 12.7 & 0.059815 & 4.68 \\
\hline 0727 & 0.716 & 5570 & 100 & 620 & 270 & 70 & 8.46 & 0.066164 & 7.80 \\
\hline $0728-1$ & 0.707 & 4950 & 65 & 260 & 280 & 30 & 14.5 & 0.028949 & 1.90 \\
\hline $0728-2$ & 1.83 & 5300 & 65 & 616 & 290 & 52 & 20.8 & 0.070493 & 3.38 \\
\hline 0731 & 0.987 & 4820 & 65 & 140 & 290 & 10 & 19.3 & 0.16433 & 8.50 \\
\hline $0802-1$ & 1.05 & 4825 & 65 & 613 & 280 & 66 & 15.7 & 0.067731 & 4.29 \\
\hline $0802-2$ & 0.991 & 5220 & 100 & 290 & 260 & 40 & 7.31 & 0.030267 & 4.10 \\
\hline 0803 & 0.684 & 5570 & 65 & 460 & 360 & 30 & 27.8 & 0.065916 & 2.40 \\
\hline 0804 & 1.35 & 5300 & 64.3 & 236 & 300 & 10 & 4.34 & 0.027938 & 6.42 \\
\hline 0806 & 0.355 & 5320 & 65 & 220 & 300 & 40 & 9.53 & 0.026755 & 2.70 \\
\hline $0807-1$ & 0.690 & 5670 & 65 & 220 & 330 & 30 & 13.7 & 0.029430 & 2.20 \\
\hline $0807-2$ & 0.952 & 5270 & 65 & 160 & 220 & 10 & 15.9 & 0.014295 & 0.900 \\
\hline 0808 & 1.12 & 4825 & 100 & 722 & 290 & 79 & 10.4 & 0.082623 & 7.90 \\
\hline 0810 & 1.00 & 5575 & 65 & 395 & 350 & 28 & 29.9 & 0.054555 & 1.82 \\
\hline $0811-1$ & 0.660 & 4920 & 100 & 510 & 290 & 40 & 11.4 & 0.058477 & 4.90 \\
\hline $0811-2$ & 0.860 & 5270 & 100 & 110 & 220 & 10 & 5.25 & 0.010033 & 1.90 \\
\hline $0814-1$ & 0.462 & 4820 & 65 & 350 & 270 & 40 & 14.6 & 0.038632 & 2.60 \\
\hline $0814-2$ & 0.430 & 5300 & 65 & 310 & 250 & 40 & 11.1 & 0.030878 & 2.70 \\
\hline 0815 & 0.656 & 4820 & 65 & 580 & 270 & 90 & 10.1 & 0.063374 & 6.30 \\
\hline $0817-1$ & 1.16 & 4825 & 65 & 322 & 330 & 27 & 23.8 & 0.041931 & 1.75 \\
\hline $0817-2$ & 1.00 & 4925 & 65 & 337 & 265 & 31 & 17.4 & 0.035241 & 2.01 \\
\hline $0817-3$ & 0.715 & 5300 & 65 & 650 & 290 & 70 & 14.6 & 0.074956 & 5.00 \\
\hline $0823-1$ & 0.358 & 4820 & 100 & 330 & 250 & 30 & 9.14 & 0.032851 & 3.60 \\
\hline $0823-2$ & 0.980 & 5300 & 65 & 510 & 280 & 50 & 15.2 & 0.057124 & 3.70 \\
\hline 0825 & 0.712 & 5570 & 85 & 100 & 320 & 90 & 15.2 & 0.12880 & 8.32 \\
\hline
\end{tabular}


Table A1

\begin{tabular}{|l|l|l|l|l|l|l|l|l|l|}
\hline $\begin{array}{c}\text { LLNL } \\
\text { ID }\end{array}$ & $\mathrm{m}_{\mathrm{b}}$ & $\begin{array}{c}\text { Bench } \\
\text { height } \\
\text { (ft) }\end{array}$ & $\begin{array}{c}\text { Delay } \\
\mathrm{ms}\end{array}$ & $\begin{array}{c}\text { \#of } \\
\text { holes }\end{array}$ & $\begin{array}{c}\text { lbs/ } \\
\text { hole }\end{array}$ & $\begin{array}{c}\text { \#of } \\
\text { delay } \\
\mathrm{s}\end{array}$ & $\begin{array}{c}\text { yield/ } \\
\text { time } \\
\text { (ton/ } \\
\mathrm{sec})\end{array}$ & $\begin{array}{c}\text { Total yield } \\
(\mathrm{kt})\end{array}$ & $\begin{array}{c}\text { Durat } \\
\text { ion } \\
(\mathrm{sec})\end{array}$ \\
\hline \hline 0827 & 1.01 & 4925 & 100 & 683 & 275 & 73 & 10.1 & 0.074118 & 7.30 \\
\hline 0828 & 0.483 & 5300 & 79.2 & 500 & 210 & 40 & 12.1 & 0.042014 & 3.34 \\
\hline 0830 & 0.732 & 4920 & 50.4 & 100 & 220 & 90 & 19.1 & 0.088203 & 4.54 \\
\hline 0831 & 0.955 & 4820 & 77.3 & 130 & 280 & 10 & 16.0 & 0.15666 & 9.20 \\
\hline $0905-1$ & 0.879 & 4920 & 65 & 530 & 270 & 30 & 22.1 & 0.056788 & 2.40 \\
\hline $0905-2$ & 0.560 & 4820 & 100 & 430 & 270 & 10 & 4.54 & 0.004581 & 1.00 \\
\hline 0906 & 1.02 & 4900 & 65 & 580 & 260 & 42 & 21.7 & 0.059507 & 2.73 \\
\hline 0907 & 0.546 & 4820 & 100 & 200 & 300 & 30 & 6.66 & 0.023913 & 3.60 \\
\hline $0908-1$ & 1.04 & 5375 & 35 & 55 & 150 & 12 & 7.75 & 0.003255 & 0.400 \\
\hline $0908-2$ & 1.08 & 5575 & 50 & 100 & 320 & 71 & 35.6 & 0.12653 & 3.55 \\
\hline 0912 & 1.01 & 5275 & 72.7 & 801 & 235 & 90 & 11.3 & 0.074279 & 6.54 \\
\hline 0913 & 0.627 & 4820 & 65 & 520 & 160 & 70 & 7.07 & 0.033147 & 4.60 \\
\hline
\end{tabular}



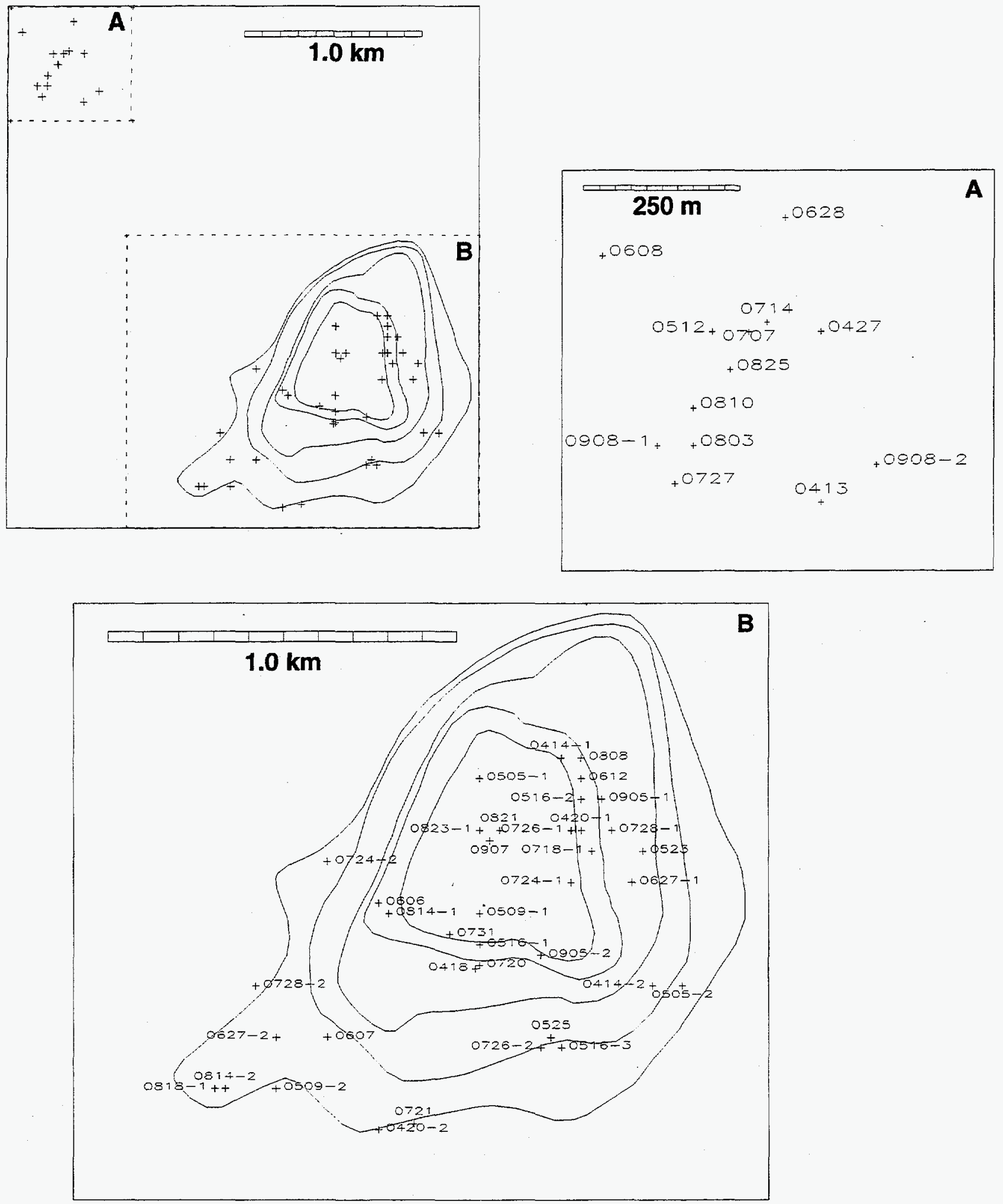

Figure A1. Locations of 51 NGC shots. The upper left map shows the locations of all shots, and insets $A$ and $B$ are smaller-scale maps showing the two distinct groups of shots. Insets $A$ and $B$ have the locations labeled with the ID field (first column) from Table A1. 
Table A2

\begin{tabular}{|c|c|c|c|c|}
\hline ID & $\begin{array}{l}\text { Cepstrum- } \\
\text { before }\end{array}$ & Cepstrum-after & Wüster-before & Wüster-after \\
\hline 0413 & ripple-fired & ripple-fired & ripple-fired & ripple-fired \\
\hline 0414_1 & ripple-fired & ripple-fired & ripple-fired & not-ripple-fired \\
\hline $0414 \_2$ & ripple-fired & not-ripple-fired & not-ripple-fired & snr \\
\hline 0418 & ripple-fired & ripple-fired & ripple-fired & ripple-fired \\
\hline $0420 \_1$ & ripple-fired & ripple-fired & ripple-fired & ripple-fired \\
\hline $0420 \_2$ & ripple-fired & not-ripple-fired & ripple-fired & not-ripple-fired \\
\hline 0427 & ripple-fired & ripple-fired & snr & not-ripple-fired \\
\hline $0505 \_1$ & ripple-fired & ripple-fired & ripple-fired & ripple-fired \\
\hline $0505 \_2$ & ripple-fired & not-ripple-fired & not-ripple-fired & snr \\
\hline 0509_1 & ripple-fired & not-ripple-fired & ripple-fired & ripple-fired \\
\hline 0509_2 & ripple-fired & ripple-fired & ripple-fired & snr \\
\hline 0512 & ripple-fired & ripple-fired & ripple-fired & snr \\
\hline $0516 \_1$ & ripple-fired & ripple-fired & ripple-fired & ripple-fired \\
\hline 0516_2 & ripple-fired & ripple-fired & ripple-fired & ripple-fired \\
\hline 0516_3 & ripple-fired & ripple-fired & ripple-fired & not-ripple-fired \\
\hline 0523 & ripple-fired & not-ripple-fired & ripple-fired & not-ripple-fired \\
\hline 0525 & ripple-fired & not-ripple-fired & ripple-fired & snr \\
\hline 0607 & ripple-fired & not-ripple-fired & ripple-fired & not-ripple-fired \\
\hline 0608 & ripple-fired & not-ripple-fired & ripple-fired & snr \\
\hline 0627_1 & ripple-fired & ripple-fired & ripple-fired & ripple-fired \\
\hline 0627_2 & ripple-fired & not-ripple-fired & not-ripple-fired & snr \\
\hline 0628 & ripple-fired & not-ripple-fired & ripple-fired & snr \\
\hline 0707 & ripple-fired & ripple-fired & ripple-fired & ripple-fired \\
\hline 0714 & ripple-fired & not-ripple-fired & ripple-fired & not-ripple-fired \\
\hline 0718_1 & ripple-fired & ripple-fired & ripple-fired & ripple-fired \\
\hline
\end{tabular}


Table A2

\begin{tabular}{|l|l|l|l|l|}
\hline \multicolumn{1}{|c|}{ ID } & \multicolumn{1}{|c|}{$\begin{array}{l}\text { Cepstrum- } \\
\text { before }\end{array}$} & Cepstrum-after & Wüster-before & Wüster-after \\
\hline \hline $0718 \_2$ & ripple-fired & ripple-fired & ripple-fired & snr \\
\hline $0724 \_1$ & ripple-fired & ripple-fired & ripple-fired & ripple-fired \\
\hline $0724 \_2$ & ripple-fired & not-ripple-fired & ripple-fired & snr \\
\hline $0726 \_1$ & ripple-fired & not-ripple-fired & ripple-fired & snr \\
\hline $0726 \_2$ & ripple-fired & not-ripple-fired & snr & snr \\
\hline 0727 & ripple-fired & ripple-fired & ripple-fired & ripple-fired \\
\hline $0728 \_1$ & ripple-fired & ripple-fired & ripple-fired & not-ripple-fired \\
\hline $0728 \_2$ & ripple-fired & not-ripple-fired & snr & snr \\
\hline 0731 & ripple-fired & ripple-fired & ripple-fired & ripple-fired \\
\hline $0802 \_1$ & ripple-fired & ripple-fired & ripple-fired & not-ripple-fired \\
\hline $0802 \_2$ & ripple-fired & not-ripple-fired & snr & snr \\
\hline 0803 & ripple-fired & not-ripple-fired & ripple-fired & not-ripple-fired \\
\hline 0804 & ripple-fired & not-ripple-fired & snr & snr \\
\hline 0806 & ripple-fired & ripple-fired & not-ripple-fired & not-ripple-fired \\
\hline $0807 \_1$ & ripple-fired & not-ripple-fired & ripple-fired & not-ripple-fired \\
\hline $0807 \_2$ & ripple-fired & not-ripple-fired & ripple-fired & snr \\
\hline 0808 & ripple-fired & ripple-fired & ripple-fired & ripple-fired \\
\hline 0810 & ripple-fired & not-ripple-fired & ripple-fired & not-ripple-fired \\
\hline $0811 \_1$ & ripple-fired & ripple-fired & ripple-fired & ripple-fired \\
\hline $0811 \_2$ & ripple-fired & not-ripple-fired & not-ripple-fired & snr \\
\hline $0814 \_1$ & ripple-fired & not-ripple-fired & snr & not-ripple-fired \\
\hline $0814 \_2$ & ripple-fired & not-ripple-fired & ripple-fired & not-ripple-fired \\
\hline 0815 & ripple-fired & ripple-fired & ripple-fired & not-ripple-fired \\
\hline $0817 \_1$ & ripple-fired & not-ripple-fired & ripple-fired & snr \\
\hline $0817 \_2$ & ripple-fired & ripple-fired & not-ripple-fired & not-ripple-fired \\
\hline $0817 \_3$ & not-ripple-fired & not-ripple-fired & not-ripple-fired \\
\hline
\end{tabular}


Table A2

\begin{tabular}{|l|l|l|l|l|}
\hline \multicolumn{1}{|c|}{ ID } & \multicolumn{1}{|c|}{$\begin{array}{c}\text { Cepstrum- } \\
\text { before }\end{array}$} & Cepstrum-after & Wüster-before & Wüster-after \\
\hline \hline $0818 \_1$ & ripple-fired & not-ripple-fired & ripple-fired & ripple-fired \\
\hline $0818 \_2$ & ripple-fired & not-ripple-fired & snr & snr \\
\hline 0821 & ripple-fired & not-ripple-fired & snr & not-ripple-fired \\
\hline $0823 \_1$ & ripple-fired & ripple-fired & ripple-fired & ripple-fired \\
\hline $0823 \_2$ & ripple-fired & ripple-fired & ripple-fired & snr \\
\hline 0825 & ripple-fired & ripple-fired & snr & ripple-fired \\
\hline 0827 & ripple-fired & not-ripple-fired & ripple-fired & not-ripple-fired \\
\hline 0828 & ripple-fired & ripple-fired & ripple-fired & ripple-fired \\
\hline 0830 & ripple-fired & ripple-fired & ripple-fired & ripple-fired \\
\hline 0831 & ripple-fired & ripple-fired & ripple-fired & ripple-fired \\
\hline 0901 & ripple-fired & ripple-fired & ripple-fired & ripple-fired \\
\hline $0905 \_1$ & ripple-fired & ripple-fired & ripple-fired & ripple-fired \\
\hline $0905 \_2$ & ripple-fired & not-ripple-fired & snr & snr \\
\hline 0906 & ripple-fired & ripple-fired & ripple-fired & ripple-fired \\
\hline 0907 & ripple-fired & not-ripple-fired & ripple-fired & not-ripple-fired \\
\hline $0908 \_1$ & ripple-fired & not-ripple-fired & not-ripple-fired & not-ripple-fired \\
\hline $0908 \_2$ & ripple-fired & ripple-fired & not-ripple-fired & ripple-fired \\
\hline 0912 & ripple-fired & ripple-fired & ripple-fired & not-ripple-fired \\
\hline 0913 & ripple-fired & ripple-fired & not-ripple-fired & ripple-fired \\
\hline
\end{tabular}


1415

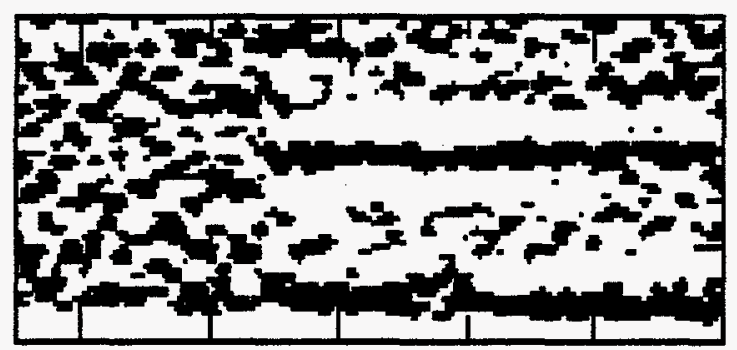

\section{4}

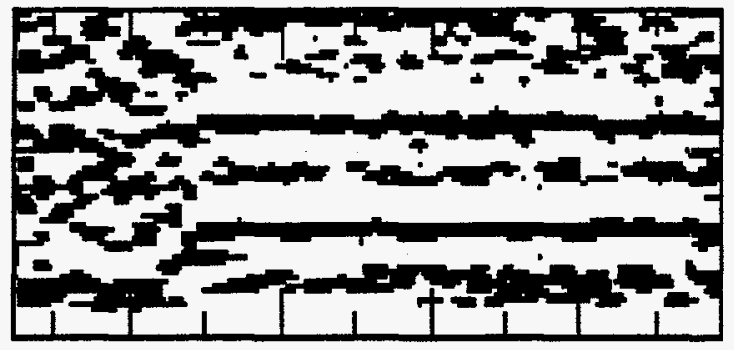

04142

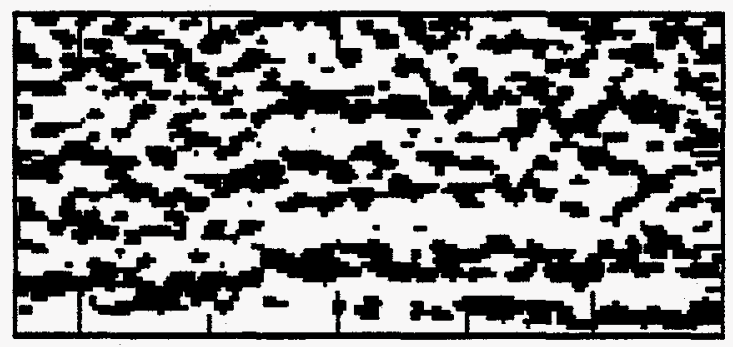

0418

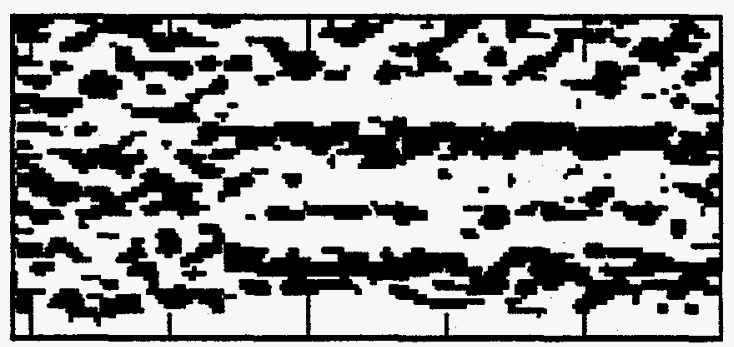

D42 1

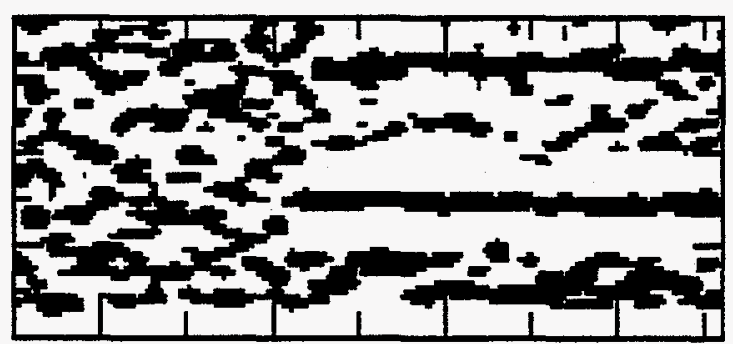

W4레 2

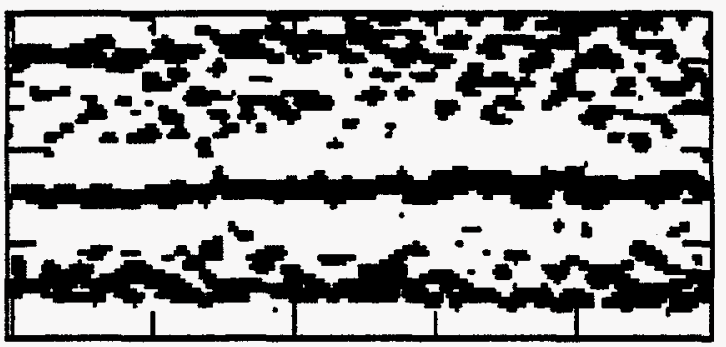

412]

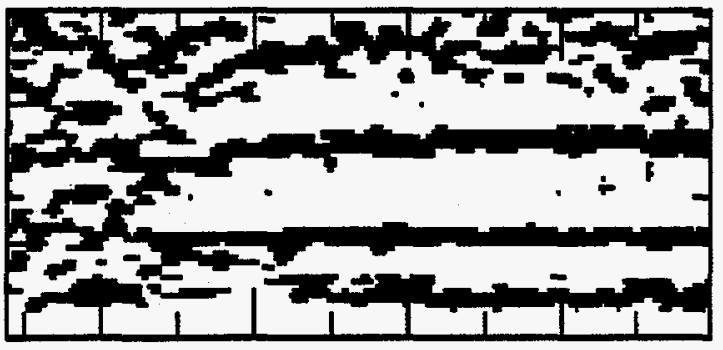

05051

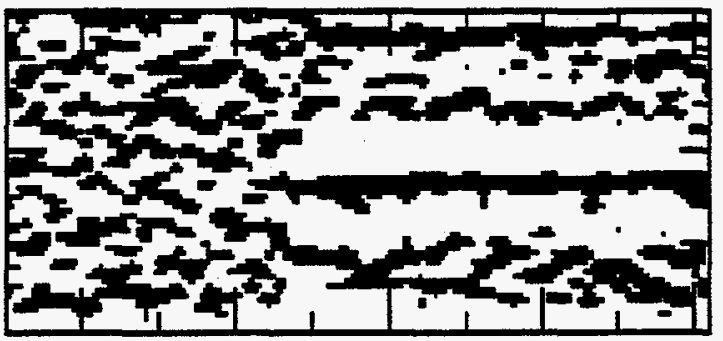

$0505 ?$

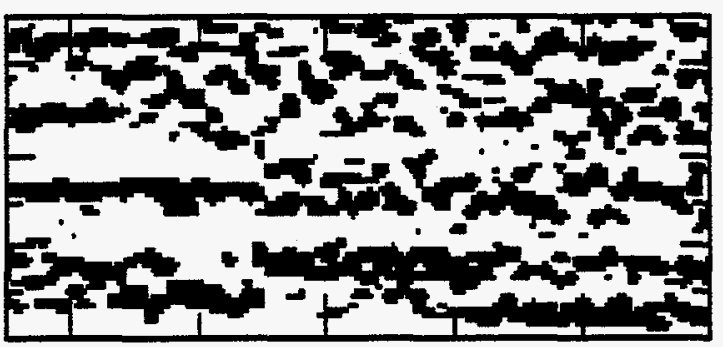

050 1

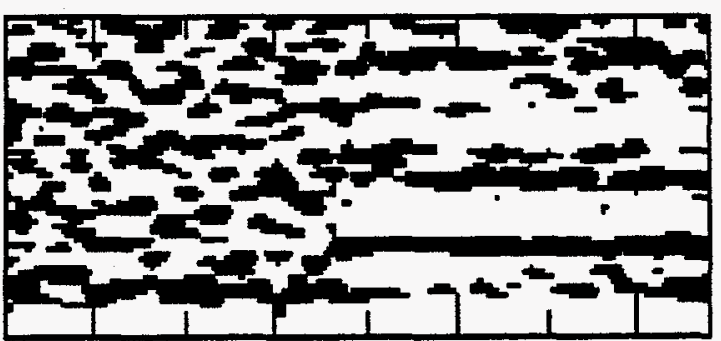


uspu 2

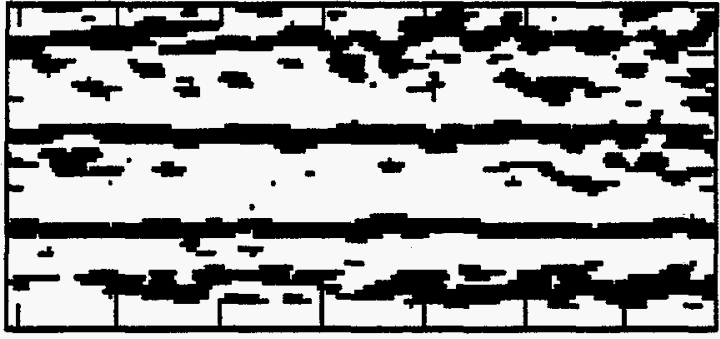

0512

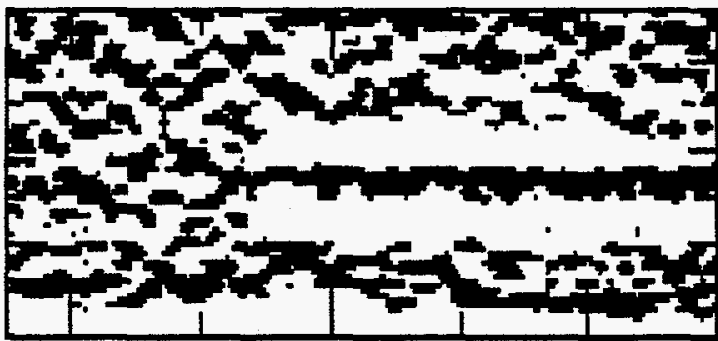

05161

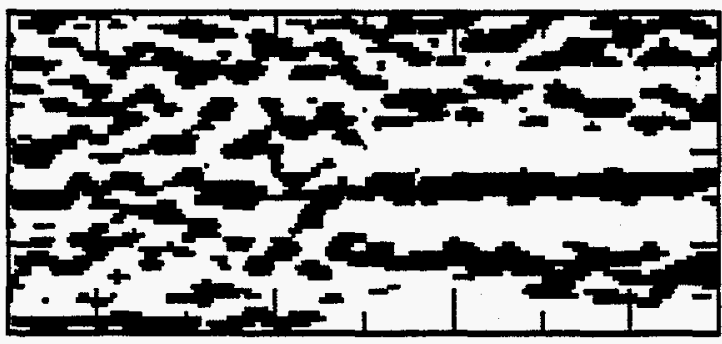

05162

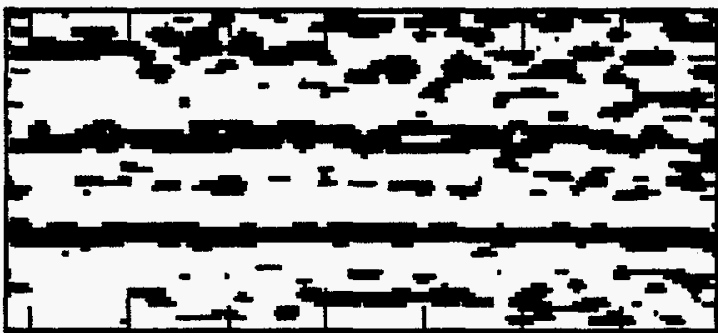

05163

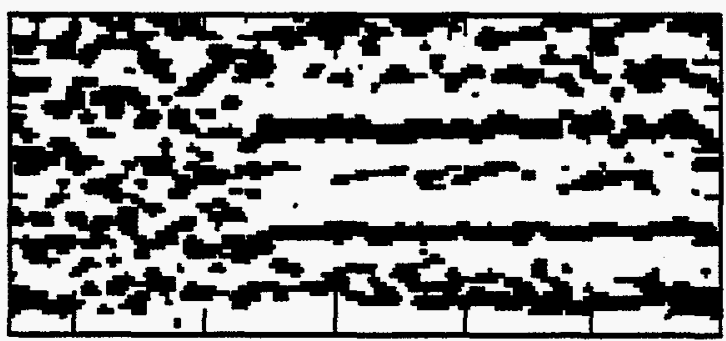

Wids

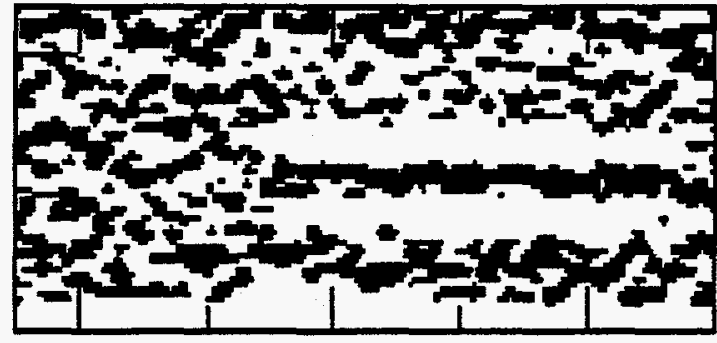

0525

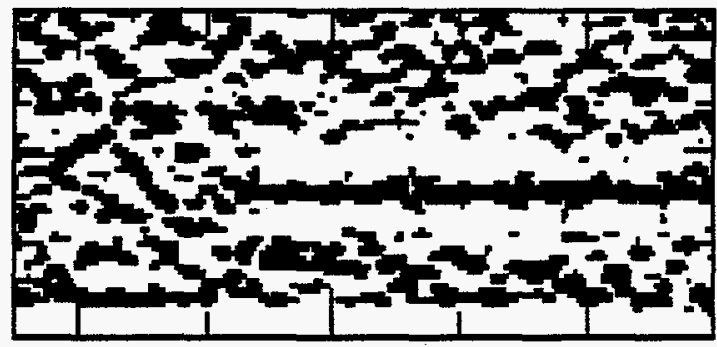

0607

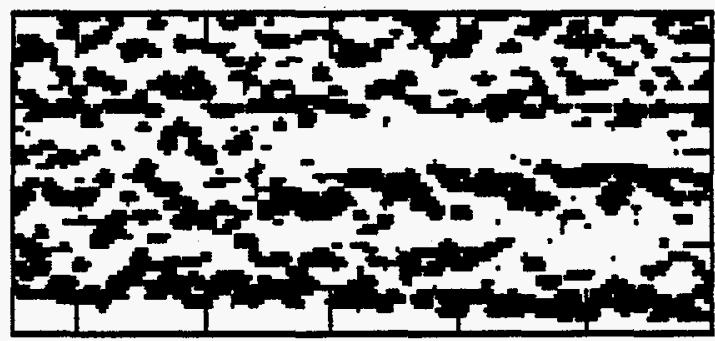

0600

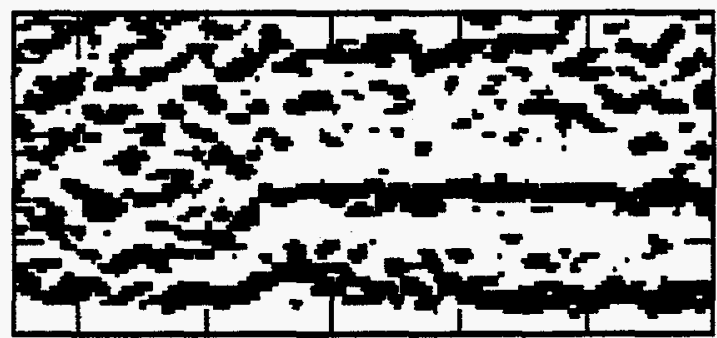

062 1

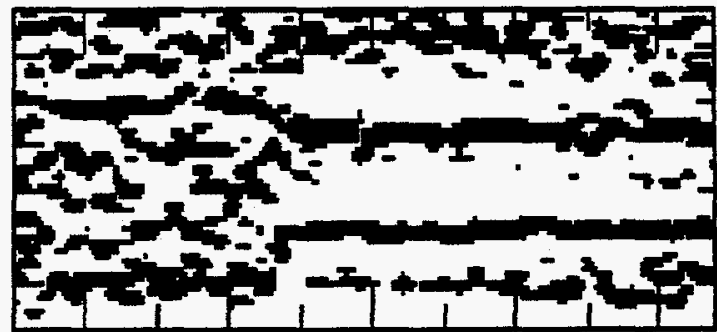


Q662 2

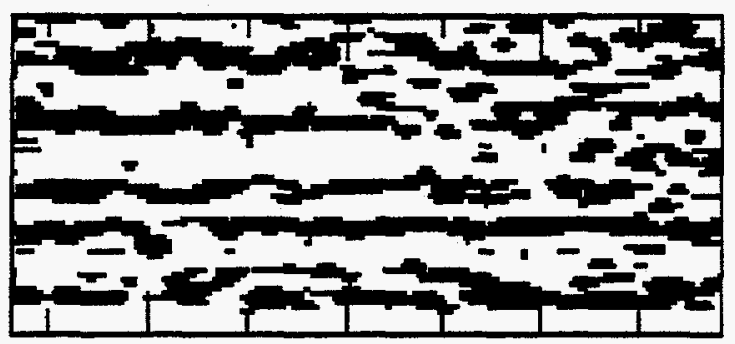

0628

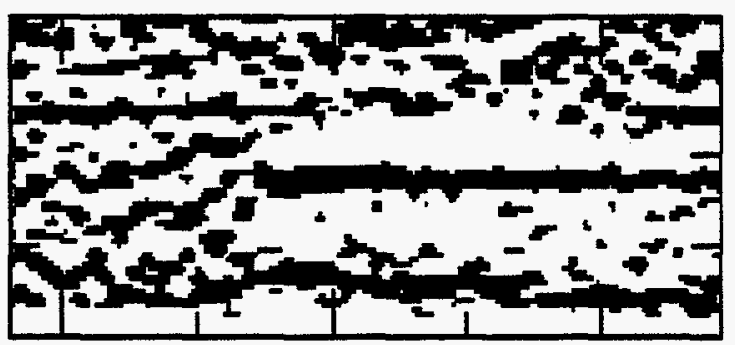

0707

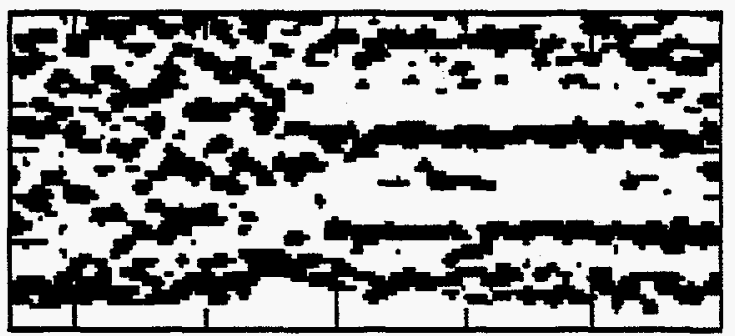

DT/4

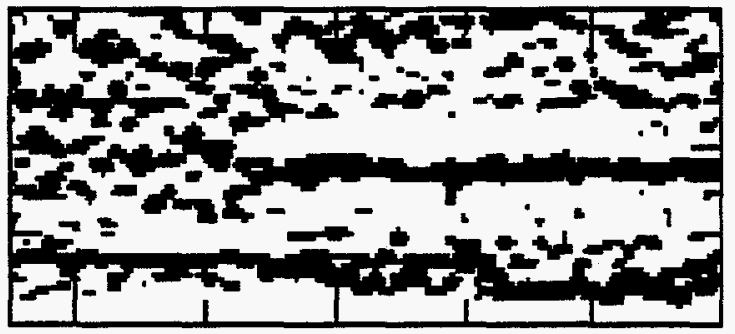

07181

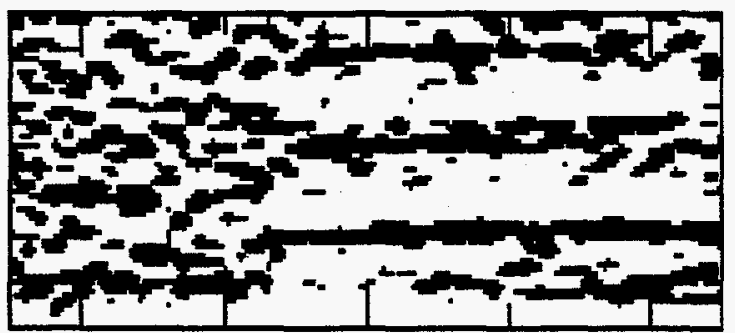

07182

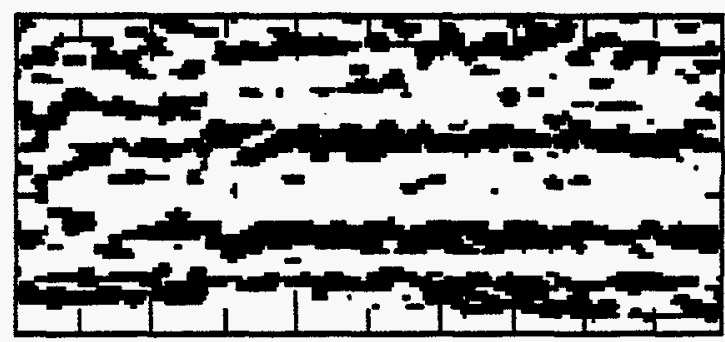

0721

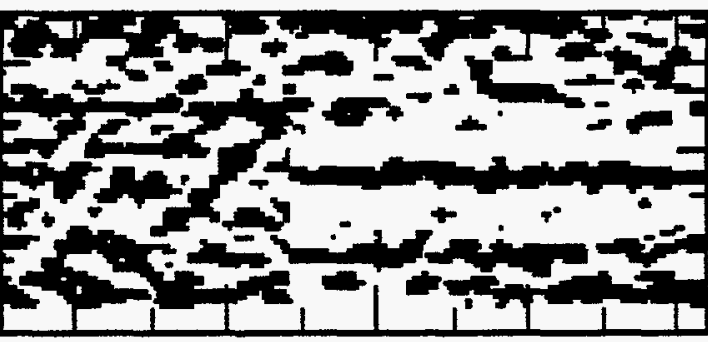

0722

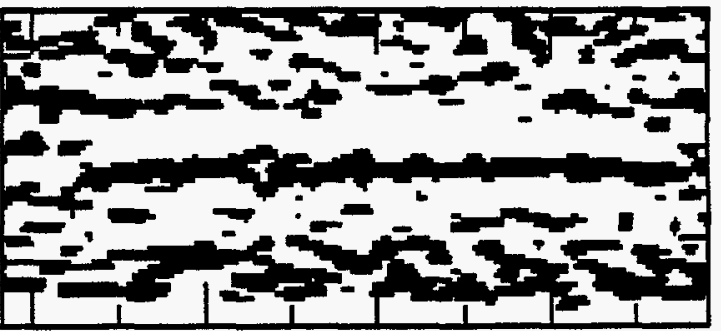

07261

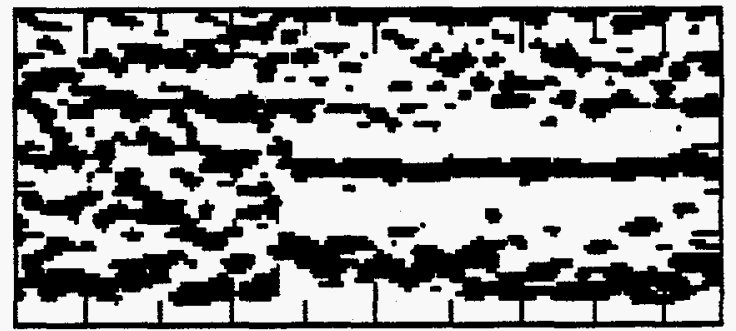

0722

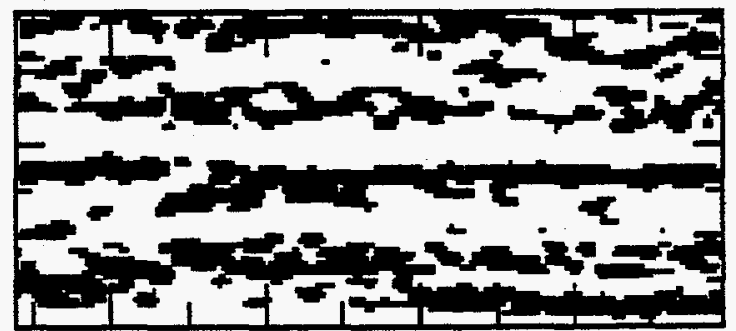


072

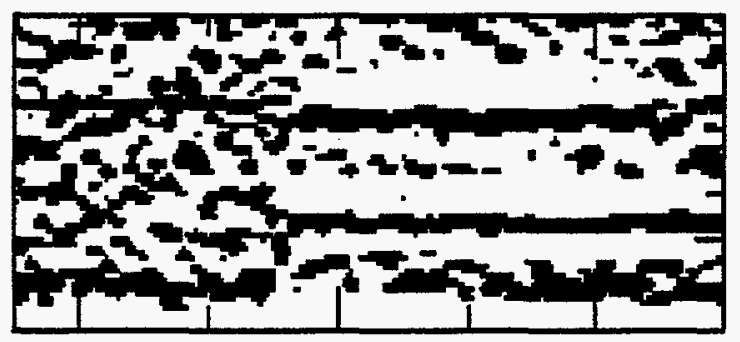

0781

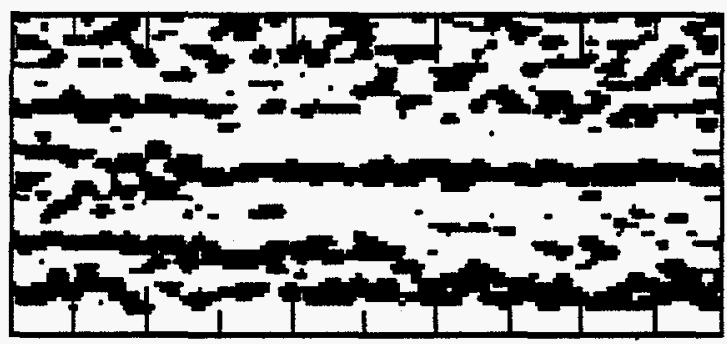

07282

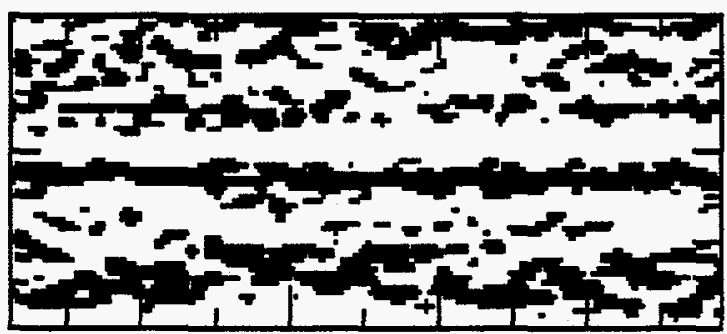

0731

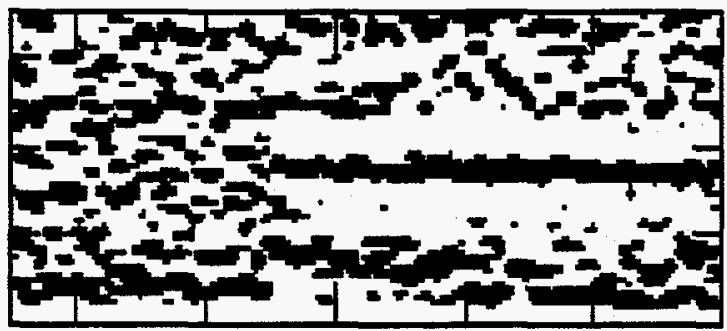

1002 1

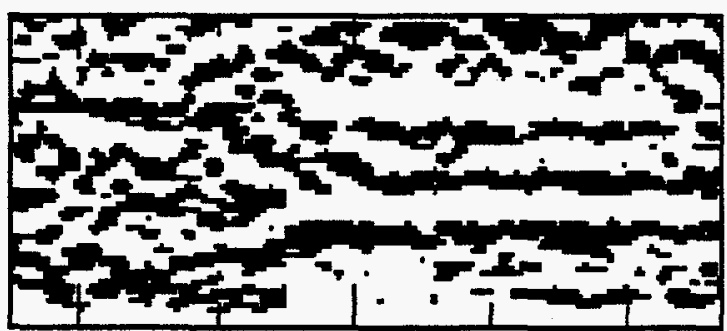

00021
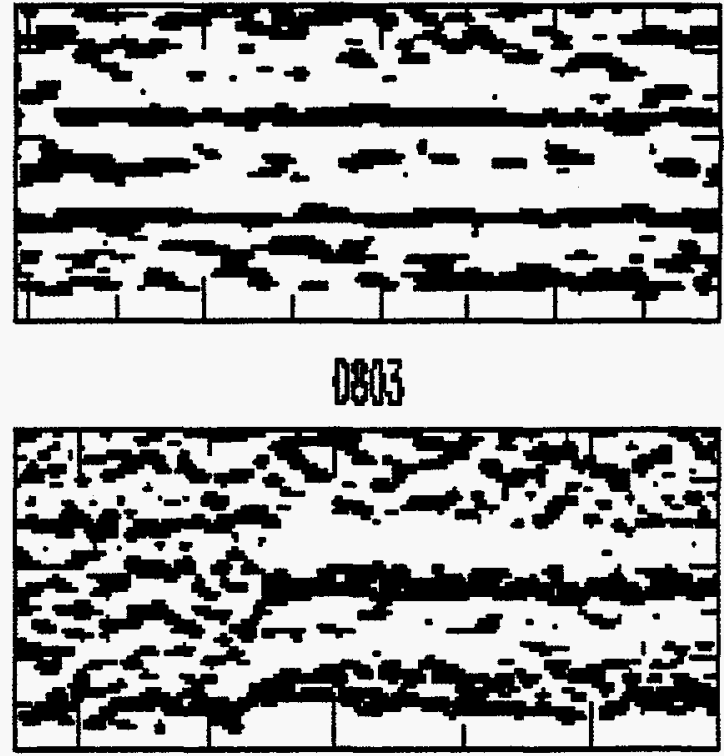

084

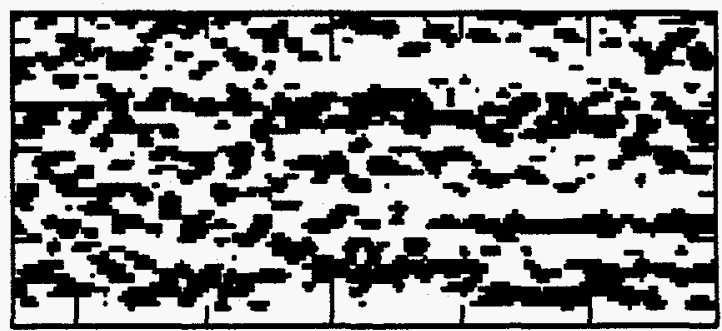

00

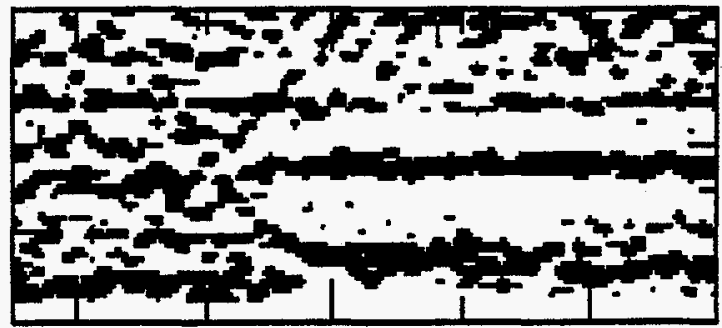

060 1

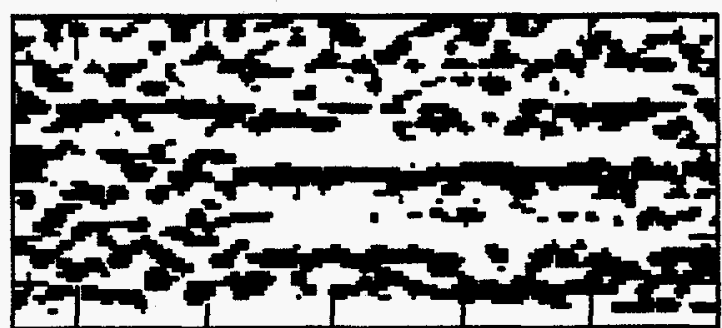


00072

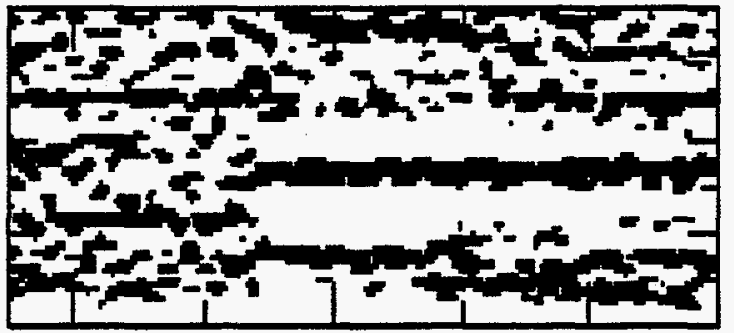

090

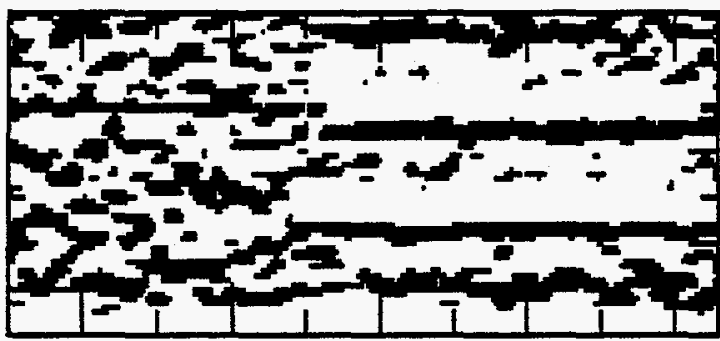

0810

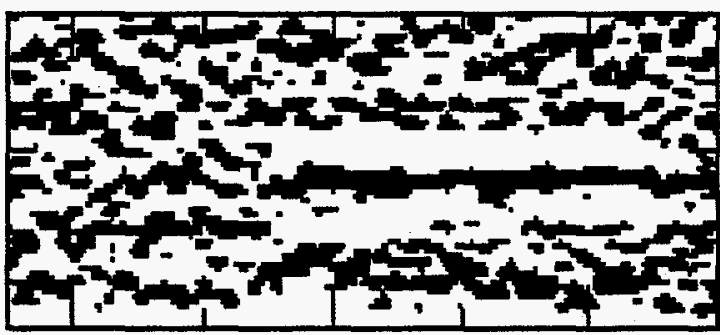

(0B111

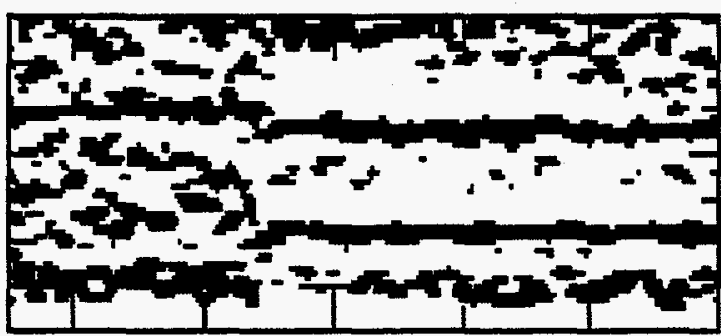

Dat11 2

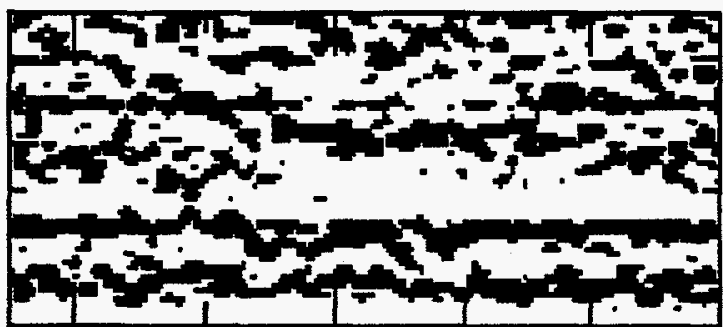

08141
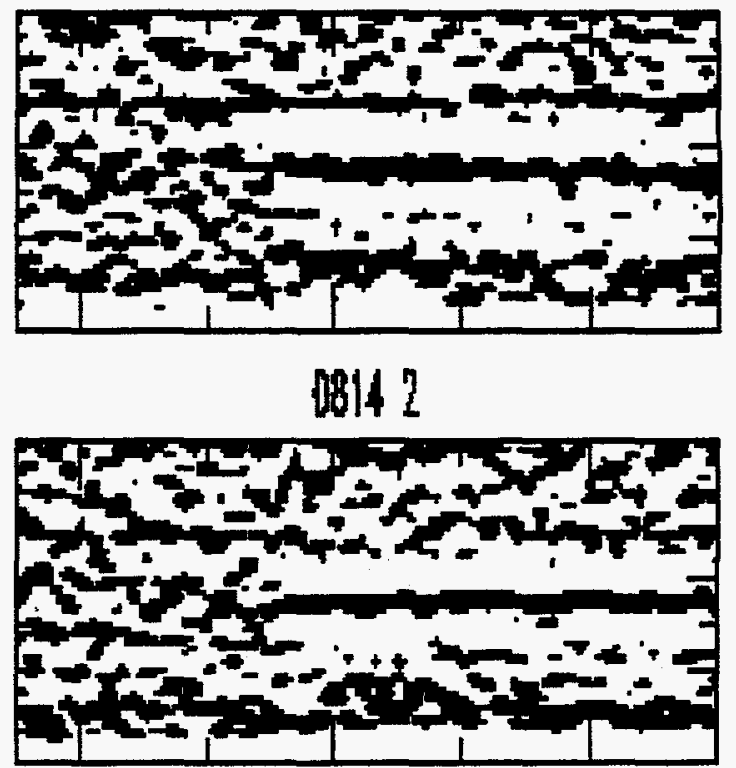

0815

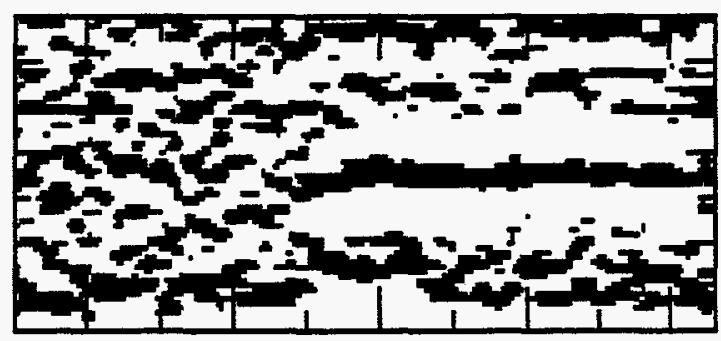

08171

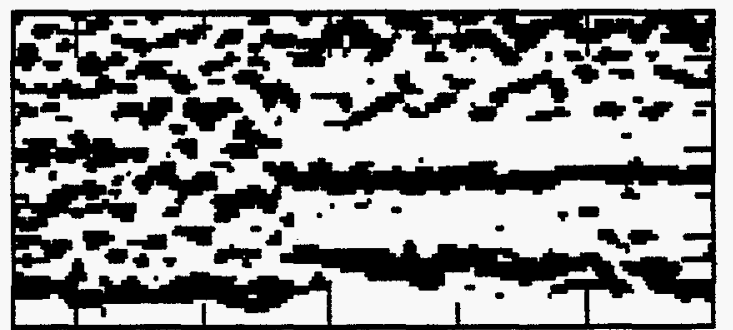

0. 172

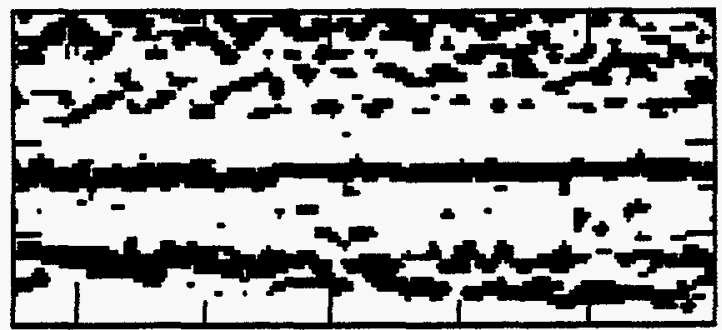


06173

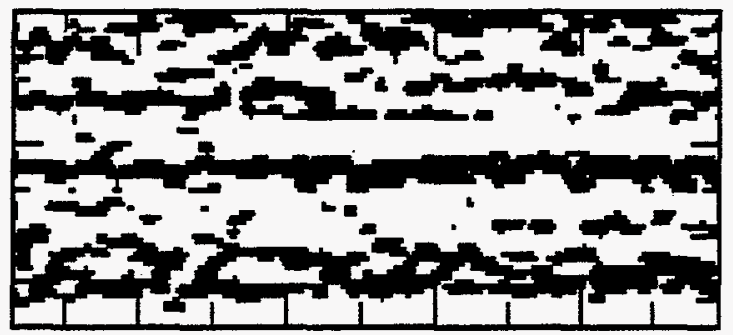

0181

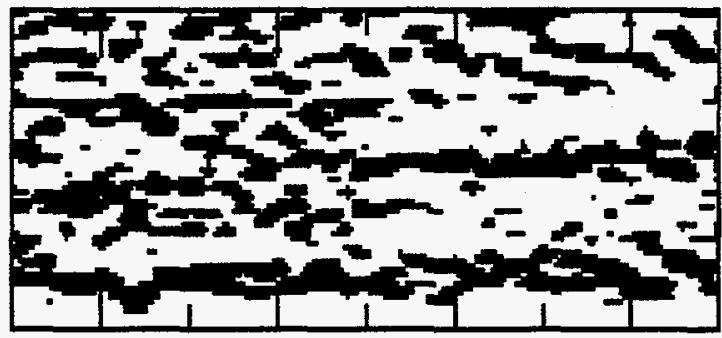

08182

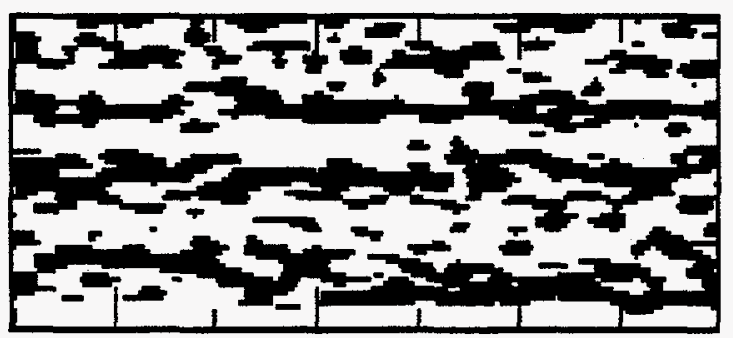

0021

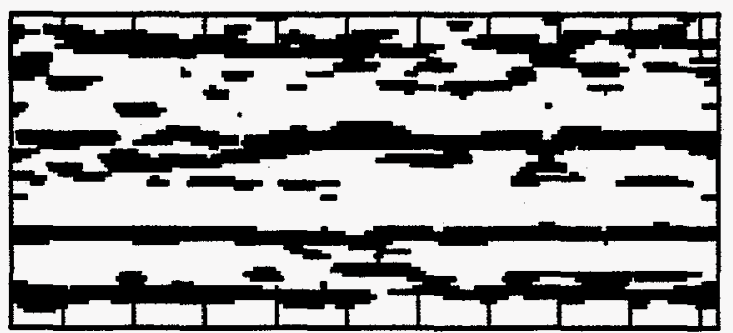

D623 1

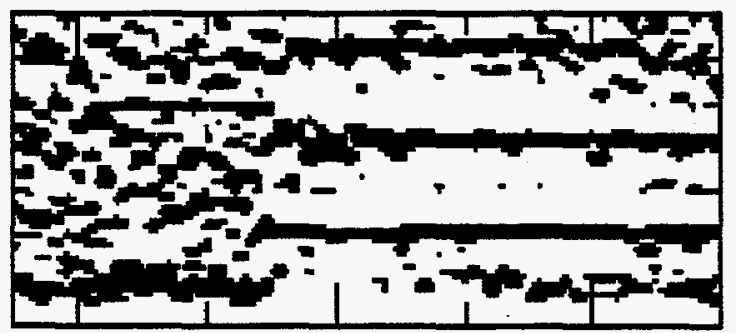

1023 1

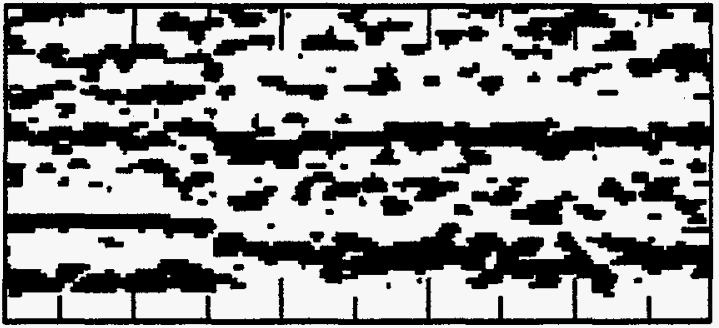

0815

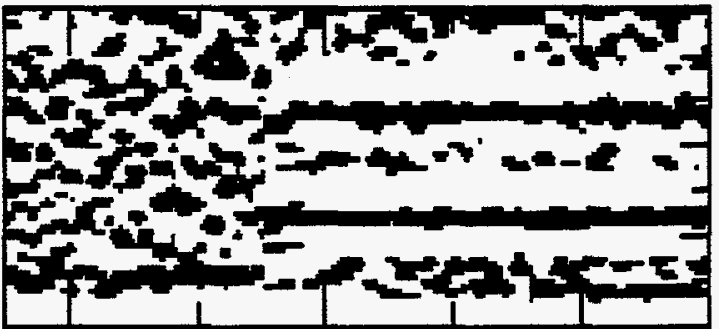

D8I

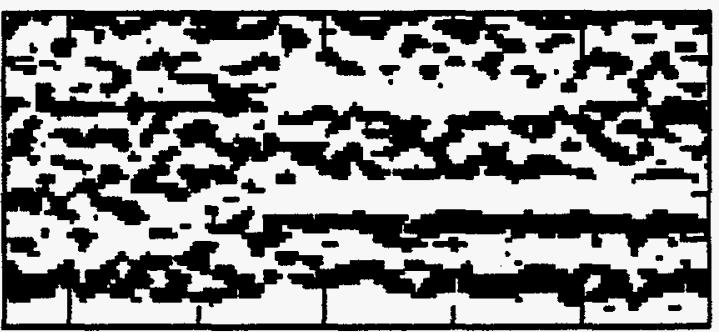

0828

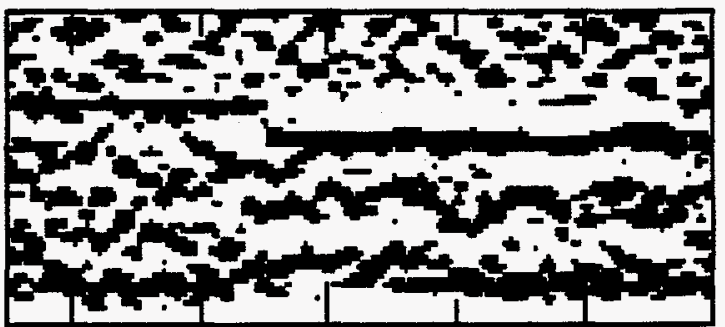

(n)

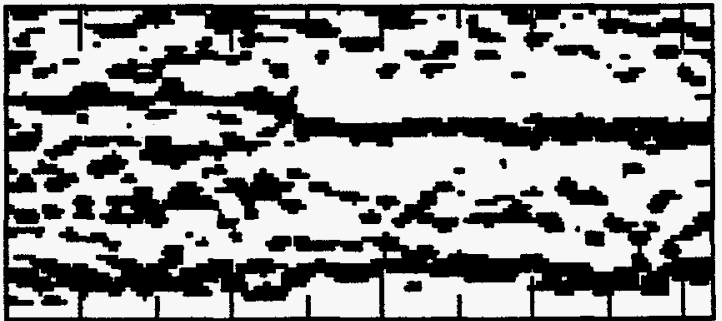


10631

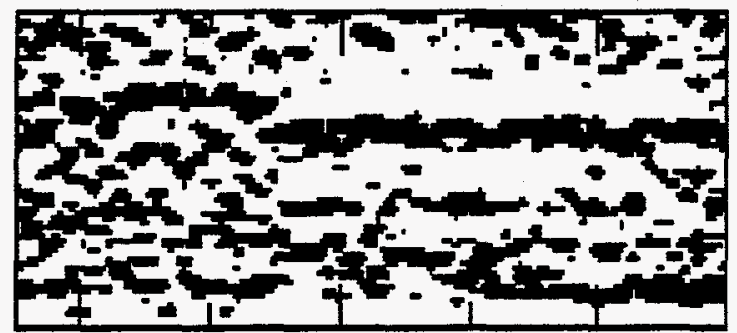

and

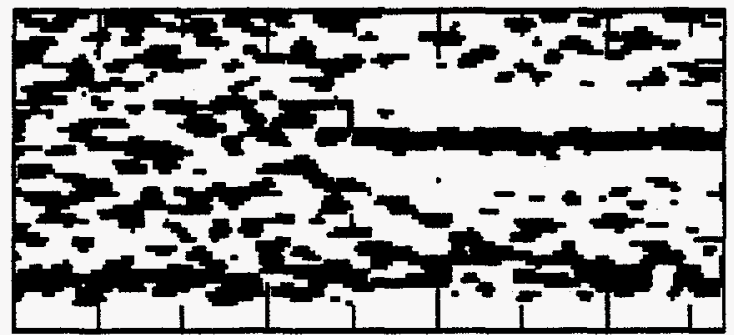

00651

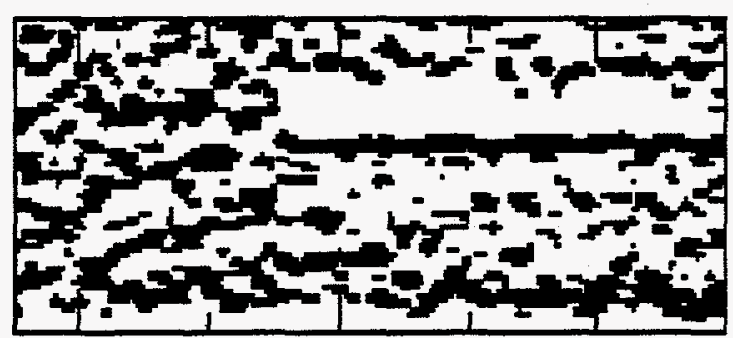

00052

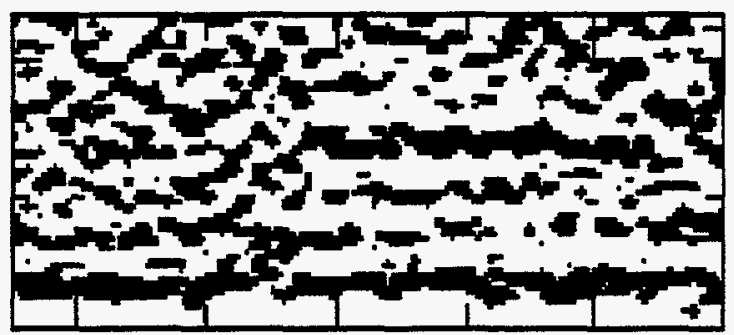

0906

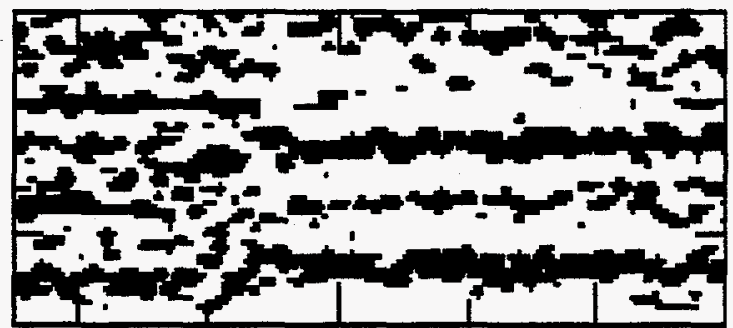

0907

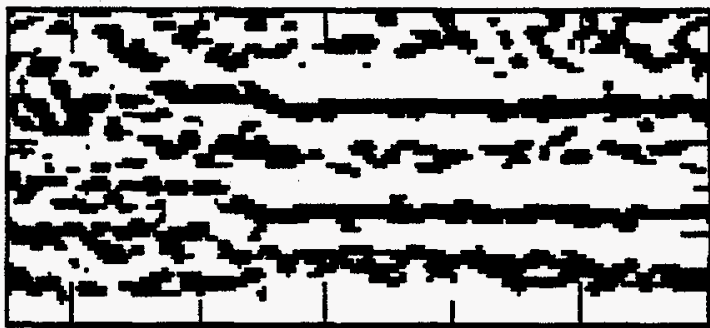

40.98 1

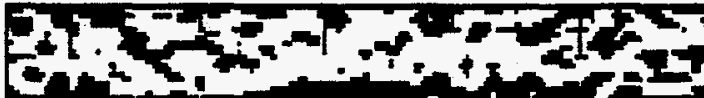

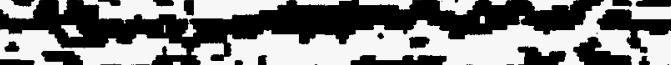

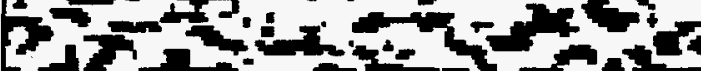

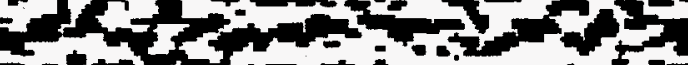
$=-++2+1$

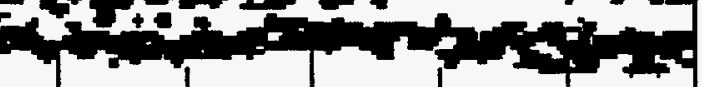

00007

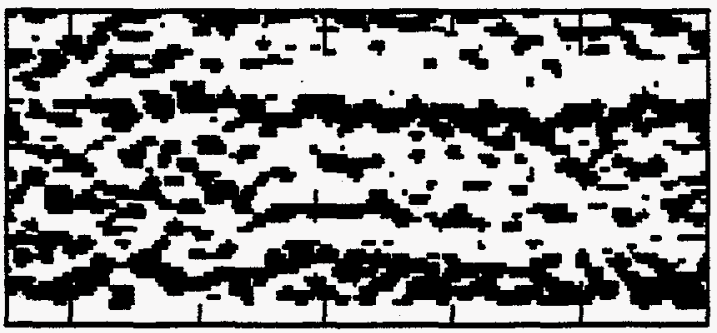

012

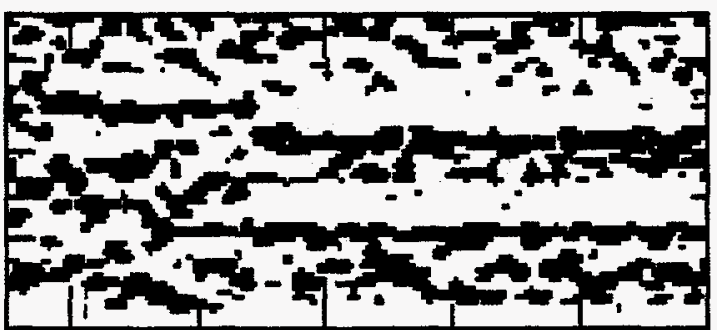

0013

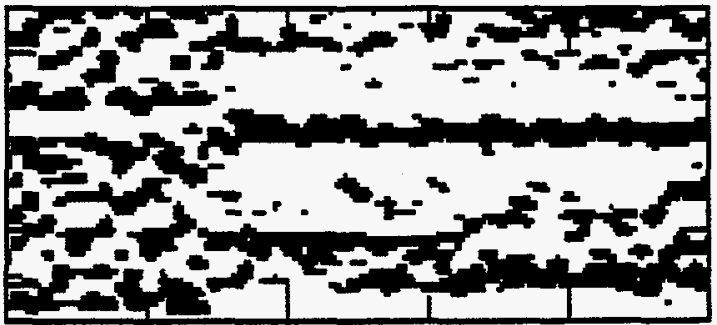


Ahern, Timothy

Ahrens, Thomas J.

Aki, Keiiti

Alexander, Shelton

Ammon, Charles

Anderson, Douglas

Archambeau, Charles B.

Archuleta, Ralph

Baker, Glenn Eli

Barazangi, Muawia

Bardzell, Richard J.

Barker, Jeffery

Basham, Peter

Baumgardt, Douglas R.

Beck, Susan

Bennett, Theron J.

Berger, Jonathan

Blandford, Robert

Bouchon, Michel

Bratt, Steve R.

Breding, Dale $\mathrm{R}$.

Brune, J.

Burdick, Lawrence

Burkhard, Norman

Campillo, Michel

Carr, Dorothe

Carrigan, Charles

Carter, Jerry A.

Casey, Leslie A.

Chan, Winston

Chun, Kin-Yip

Cipar, John J.

Cogbill, Allen $\mathrm{H}$.

Comer, Robert

Cormier, Vernon F.

Dainty, Anton W.

Day, Steven M.

Denny, Marv

Der, Zoltan A.

Dickinson, Stanley K.

Doser, Diane I.

Douglas, Alan

Farrell, William

Fehler, Michael C.

Ferguson, John

Fisk, Mark D.
Flatte, Stanley

Frankel, Arthur

Garbin, Douglas

Given, Holly

Given, Jeffrey W.

Glenn, Lewis A.

Goldstein, Peter

Grant, Lori T.

Gupta, Indra N.

Gustafson, Richard

Hagedorn, Dan

Hannon, Wilard J.

Harben, Phillip

Harjes, Hans-Peter

Harkrider, David

Harris, Dave

Harvey, Danny

Hedlin, Michael

Helmberger, Donald V.

Henger, Manfred

Herrin, Eugene T.

Herrington, Preston B.

Herrmann, Robert

Heuze, François

Hsu, Vindell

Husebye, Eystein S.

Hutchings, Larry

Israelsson, Hans

Jarpe, Stephen

Jih, Rong-Song

Johnson, Lane $\mathrm{R}$.

Jordan, Thomas $\mathrm{H}$.

Kadinsky-Cade, Katharine

Kafka, Alan

Keller, Randy

Kennett, Brian L. N.

Kisslinger, Carl

Knowles, Skip

Korhonen, Heikki

Kvaerna, Tormod

Ladd, Anthony

Langston, Charles

Lay, Thorne

Leith, William

Linger, Don

Malin, Peter
Massinon, Bernard

Mayeda, Kevin

McCartor, Gary

McCormack, David

McEvilly, Thomas V.

McGarr, Art

McLaughlin, Keith L.

McNally, Karen

McNamara, Dan

Mechler, Pierre

Menke, William

Minster, Jean-Bernard

Mitchell, Brian J.

Moran, Bill

Morrow, Richard J.

Mykkeltveit, Svein

Nakanishi, Keith K.

$\mathrm{Ni}$, James

North, Robert G.

Orcutt, John A.

Owens, Thomas J.

Passow, Richard

Patton, Howard J.

Phinney, Robert A.

Pomeroy, Paul

Priestley, Keith

Prothero, William

Pulli, Jay J.

Randall, George

Reinke, Robert E.

Richards, Paul G.

Ringdal, Frode

Rivers, Wilmer

Rodgers, Arthur

Rodgers, Peter W.

Rohay, Alan C.

Romanowicz, Barbara

Rothe, George $\mathrm{H}$.

Russell, David R.

Ryall, Alan S.

Saikia, Chandan K.

Sammis, Charles G.

Schlittenhardt, Joerg

Schult, Frederick

Schwartz, Susan Y.

Sereno, Jr., Thomas J. 
Shapira, Avi

Simpson, David

Smith, Albert T.

Stevens, Jeffrey L.

Stump, Brian

Swanger, Henry J.

Sweeney, Jerry

Sykes, Lynn

Taylor, Steven R.

Teng, Ta-liang

Toksoz, M. Nafi

Turnbull, Lawrence

Van der Vink, Gregory

Velasco, Aaron

Vernon, Frank L.

Wallace, Terry C.

Walter, William R.

Weaver, Thomas $T$.

Wu, Francis T.

Zollweg, James

Zucca, Jay 